\title{
Operational Considerations and Comparisons of the Saturn, Space Shuttle and Ares Launch Vehicles
}

\author{
Craig Cruzen \\ NASA Marshall Space Flight Center \\ Huntsville, AL 35812 \\ 256-544-8658 \\ craig.cruzen@nasa.gov
}

\author{
Dr. Greg Chavers \\ NASA Marshall Space Flight Center \\ Huntsville, AL 35812 \\ 256-544-5541 \\ greg.chavers@nasa.gov
}

\author{
Jerry Wittenstein \\ International Space Systems, Inc. \\ Huntsville, AL 35812 \\ 256-544-2047 \\ jerry.wittenstein-1@nasa.gov
}

\begin{abstract}
The United States (U.S.) space exploration policy has directed the National Aeronautics and Space Administration (NASA) to retire the Space Shuttle and to replace it with a new generation of space transportation systems for crew and cargo travel to the International Space Station, the Moon, Mars, and beyond. As part of the Constellation Program, engineers at NASA's Marshall Space Flight Center in Huntsville, Alabama are working to design and build the Ares I, the first of two large launch vehicles to return humans to the Moon. A deliberate effort is being made to ensure a high level of operability in order to significantly increase safety and availability as well as reduce recurring costs of this new launch vehicle. It is the Ares Project's goal to instill operability as part of the requirements development, design and operations of the vehicle. This paper will identify important factors in launch vehicle design that affect the operability and availability of the system. Similarities and differences in operational constraints will also be compared between the Saturn V, Space Shuttle and current Ares I design. Finally, potential improvements in operations and operability for large launch vehicles will be addressed. From the examples presented, the paper will discuss potential improvements for operability for future launch vehicles. ${ }^{12}$
\end{abstract}

\section{TABle OF Contents}

1. INTRODUCTION.. 1

2. Overview of The Constellation Program and

Ares Launch Vehicles 2

3. Historical Perspectives on The SATURN V AND SPACE SHUTTLE

4. What IS OPERABILITY AND HoW Do YOU DESIGN IT INTO A LAUNCH VEHICLE? .

5. COMPARISONS OF LAUNCH OPERATIONS-SATURN V, SPACE SHUTTLE \& ARES I... 6. OPERATIONS \& OPERABILITY IMPROVEMENTS FOR FUTURE LAUNCH VEHICLES. ... 11

\footnotetext{
1

1 "U.S. Government work not protected by U.S. copyright." For U.S. Government employees only.

${ }^{2}$ IEEEAC paper \#1389, Version Final: 2009 1:9
}

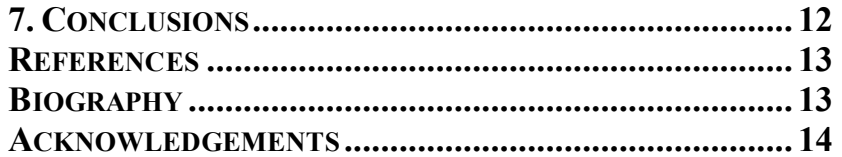

\section{INTRODUCTION}

The National Aeronautics and Space Administration (NASA) is charting a renewed course for exploration, with the fielding of a new human-rated space transportation system to replace the venerable Space Shuttle, which will be retired after construction is completed on the International Space Station (ISS). Powering the future of U.S. space exploration will be the Ares I crew launch vehicle, which will transport the Orion crew exploration vehicle to orbit where it will rendezvous with the ISS or the Altair lunar lander, which will be delivered by the Ares V cargo launch vehicle. This new exploration infrastructure will allow astronauts to once again leave low-Earth orbit for extended lunar missions and preparation for the first long-distance journeys to Mars [1].

NASA's Constellation Program is the corner stone of America's space exploration policy. The schedules, vehicles, and an overview of the strategy are important to understand as key pieces of a sustainable and robust roadmap for exploration. While new technologies, complicated spacecraft designs and a stirring plan for lunar rediscovery are all elements of Constellation, arguably the most important concept of all is the focus that NASA is placing on operability of the spacecraft and facilities. For it is this focus that will enable the growth and acceleration of exploration, and allow for development budgets and experienced designers when it is time for future elements such as heavy lift launchers, landers, surface habitats, and eventually Mars exploration spacecraft (design and development in parallel with operations) [2].

After describing the Constellation Program strategy and roadmap, this paper will look back at NASA's two previous and highly successful crewed launch vehicles; the Saturn V 
from the first lunar campaign; and the Space Shuttle, the world's first reusable spacecraft. The paper will describe what operability for a launch vehicle means in terms of design requirements and availability. The paper will then compare and contrast operations concepts and constraints of the Saturn V, Space Shuttle launch vehicle to Ares. From the examples presented, the paper will discuss potential improvements for operability for large launch vehicles. Finally conclusions will be presented that outline ways that NASA is working to streamline operational concepts and design for operability, which will reduce lifecycle costs and promote sustainable space exploration.

\section{OVERVIEW OF THE CONSTEllation Program AND ARES LAUNCH VEHICLES}

The U.S. Space Exploration Policy was enacted in 2004, was authorized into law by Congress and is articulated in NASA's 2006 Strategic Plan. NASA's goals regarding exploration are:

- Complete International Space Station construction

- $\quad$ Retire the Space Shuttle after 2010

- $\quad$ Launch the Orion crew exploration vehicle by 2014

- $\quad$ Return to the Moon by 2020

- Extend human presence across the solar system

- Implement a sustained human \& robotic program

NASA recognizes that Space Shuttle missions and ISS expeditions are active parts of exploration. New lessons and techniques for living and working in space are learned on every mission. Improvements in planned operations for the Constellation vehicles are based on these lessons as well as from other launch vehicles and space systems [3].

The ultimate goal of Constellation is to explore beyond the boundaries of our current capability. To accomplish this and the other goals listed above, new vehicles must be developed that have increased performance over existing systems and have a lower operating and life cycle cost. The current operational concept envisions a fleet of vehicles shown in Figure 1.

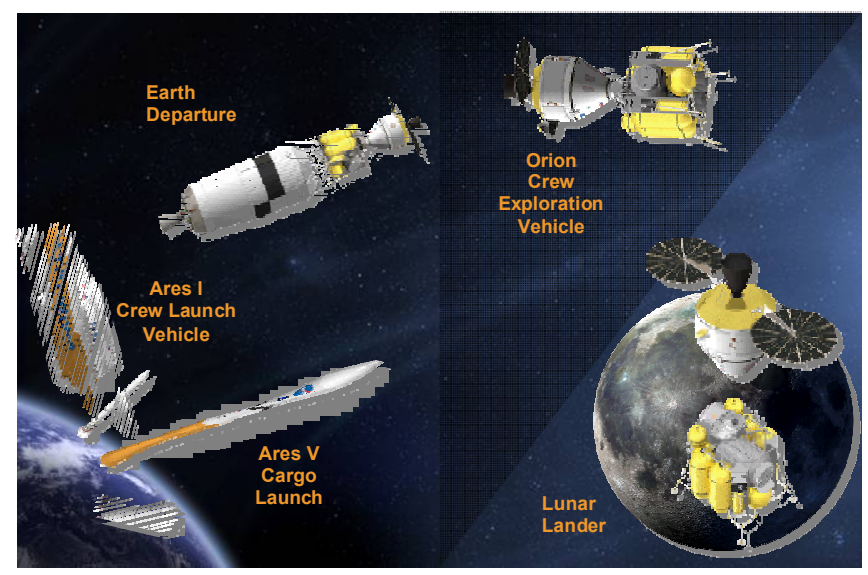

Figure 1 - The Constellation Fleet of Vehicles

NASA's newest rockets, named for the Greek god Ares, will return humans to the Moon and later take them to Mars. The Ares I will be able to place $56,000 \mathrm{lb}(25,400 \mathrm{~kg})$ in lowEarth orbit. Ares V will be used to carry cargo and the components needed to go to the Moon and later to Mars. It will be able to lift more than $410,000 \mathrm{lbs}(185,970 \mathrm{~kg})$ to low-Earth orbit.

The Orion spacecraft will be capable of carrying crew and cargo to the ISS. It will also be able to rendezvous with a lunar landing module in low-Earth orbit to carry crews to the Moon. Orion's design borrows its shape from the capsules of the past, but takes advantage of 21 st century technology in computers, electronics, life support, propulsion and thermal protection systems. Altair, the lunar lander launched by the Ares V, will be capable of landing four astronauts on the Moon, providing life support and a base for weeklong initial surface exploration missions and returning the crew to the Orion spacecraft that will bring them home to Earth.

Ares I and Ares $V$ - New Launch Vehicles for Exploration The Ares Projects Office at NASA's Marshall Space Flight Center in Huntsville, Alabama is tasked to provide the Ares I crew launch vehicle and Ares V cargo launch vehicle space transportation systems. Safe, reliable, and costeffective space transportation is a foundational piece of America's future in space. And thus, NASA has developed an aggressive, yet realistic, multiyear plan and has implemented a rigorous systems engineering approach [2]. Figure 2 reflects the schedule to develop and implement the Constellation Program and achieve the goal of returning humans to the lunar surface by 2020 [4]. 


\section{NASA's Exploration Roadmap}

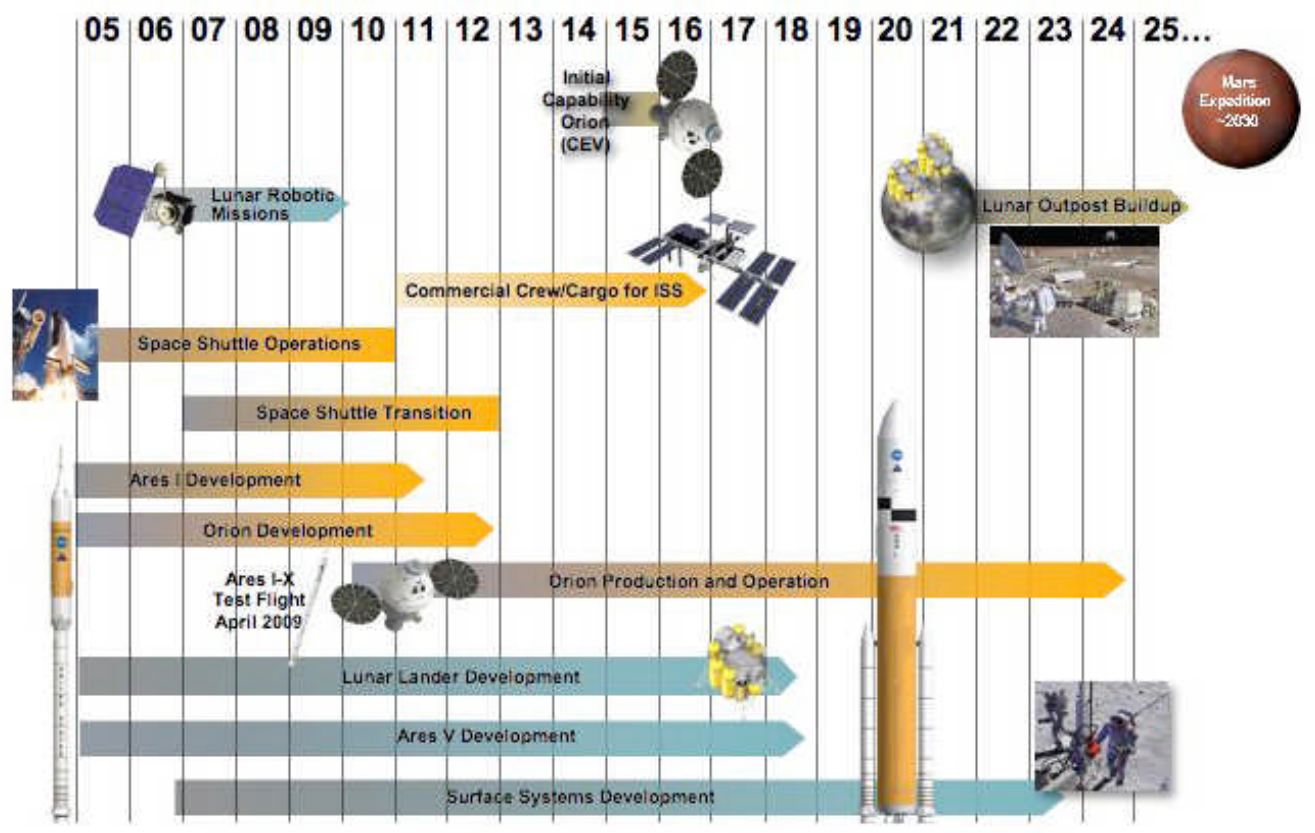

Figure 2 - NASA’s Space Exploration Roadmap

Ares I-Mission and System Description

The Ares I is a Space Shuttle-derived two-stage launch vehicle. The Ares I is comprised of a five-segment reusable solid rocket first stage booster, and an upper stage, which is a liquid oxygen (LOX) and liquid hydrogen (LH2) system powered by a single $\mathrm{J} 2 \mathrm{X}$ engine. More details regarding the Ares I vehicle elements are described below. There are two missions currently planned for the Ares I. The first is to provide services to the ISS. The second mission is to deliver the Orion with crew to a low-Earth orbit to rendezvous with the Ares V Earth Departure Stage. Figure 3 shows the Ares I and Ares $\mathrm{V}$ elements and Figure 4 provides a direct comparison of the Shuttle, Ares and Saturn vehicles [1].

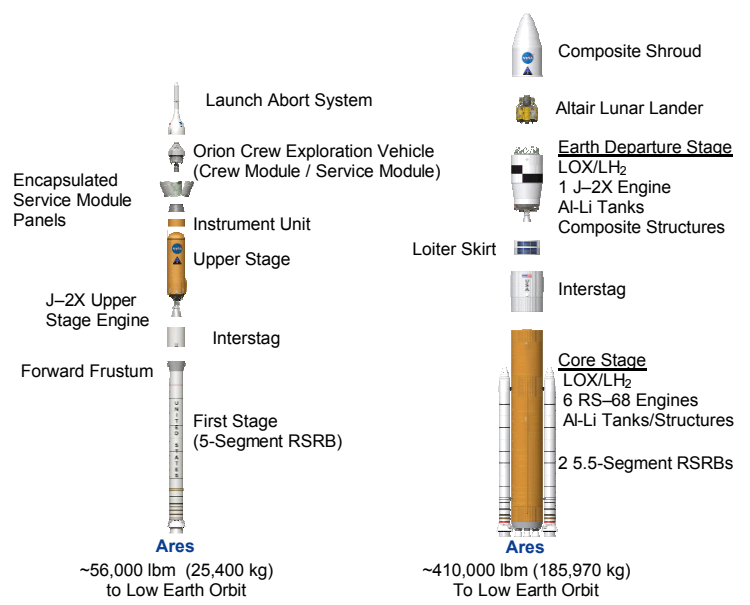

Figure 3 - Configurations of the Ares I and Ares V launch pad to an altitude of approximately 194,000 feet (59 $\mathrm{km})$. On the pad, the Ares I FS supports the entire weight of the vehicle and transmits the weight load through the structure to a mobile launch platform and stability/dampening arm connected to the launch umbilical tower. The Ares I FS has a sea-level thrust of 3.3 million lbs $(14,679 \mathrm{kN})$ at launch. It provides 100 percent of the thrust at liftoff and accelerates the Ares I to over 3,000 miles per hour $(4,828 \mathrm{~km} / \mathrm{hr})$ before separating from the Upper Stage. Ares has a project goal to recover and reuse a majority of the components of the FS and thus they are being designed for 20 flights. To facilitate this, a deceleration parachute system is required to provide velocity and attitude control from separation to water impact. The FS is made up of a forward assembly, aft assembly and five solid rocket motor casting segments. The segmented motor design provides flexibility in fabrication, transportation, and handling. The FS forward assembly includes the deceleration system as well as the majority of the avionics components. The forward assembly also provides the interface with the Upper Stage [1].

The five-segment motor design was derived from the Space Shuttle Reusable Solid Rocket Motor (RSRM). To distinguish the five-segment motor from RSRM, it has been designated the RSRMV, with the " $V$ " representing five segments instead of the four segments utilized on RSRM.

The RSRMV's subsystem consists of a combination of heritage solid rocket booster hardware and new hardware designed to meet the Ares requirements.

\section{Ares I First Stage}

The Ares I First Stage (FS) five-segment solid rocket motor provides the main thrust to lift the Ares I vehicle off the 


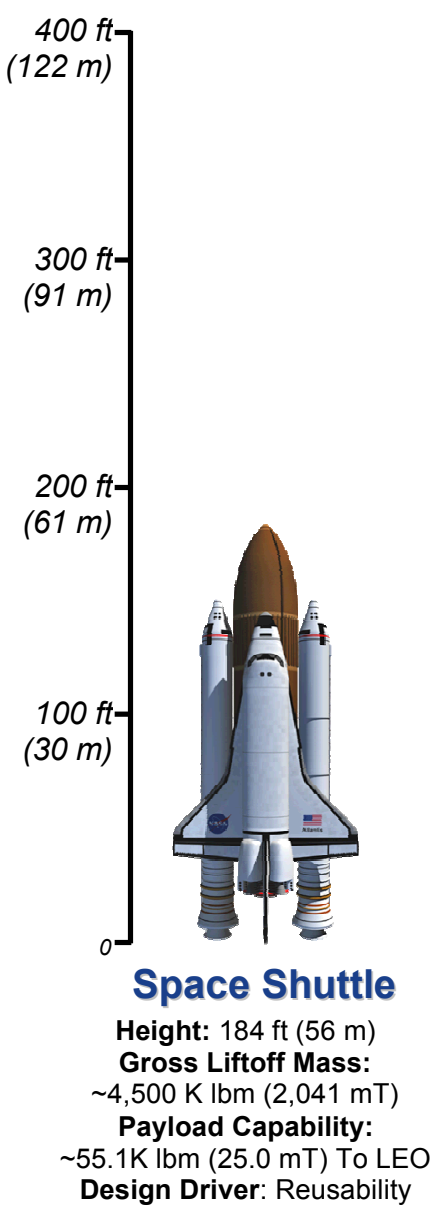

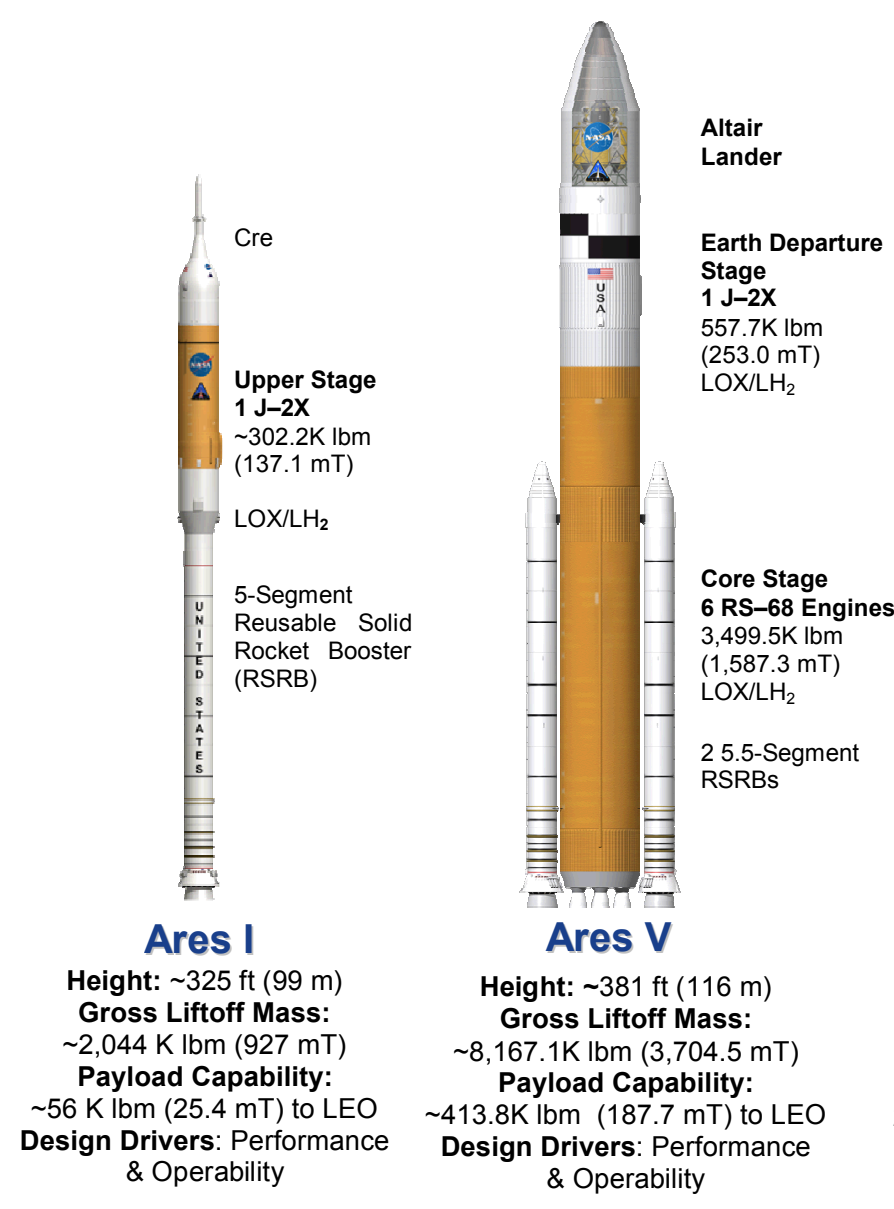

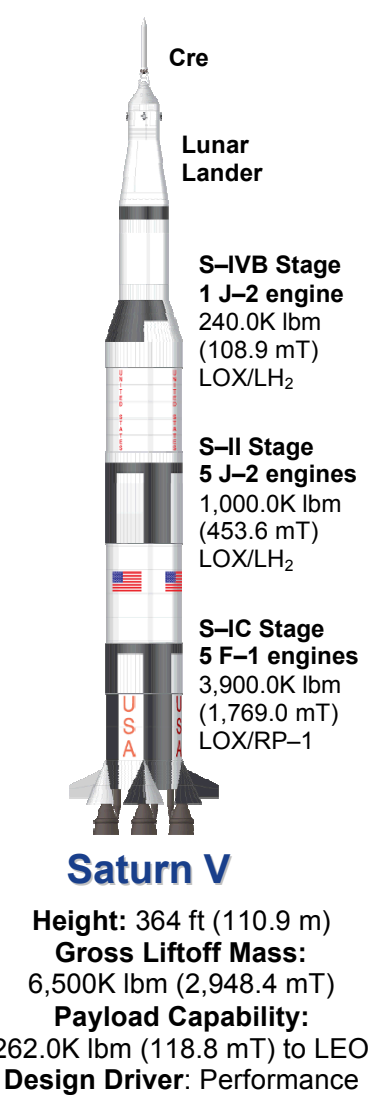

Figure 4 - Launch Vehicle Comparisons

\section{Ares I Upper Stage}

The Ares I Upper Stage extends from the FS forward frustum to the Orion adapter. The Upper Stage provides the control electronics for the entire Ares I launch stack, as well as the systems required to perform FS separation.

The Upper Stage consists of three major components: the Instrument Unit (IU), the Core Stage (also called the Tank Assembly) and the Interstage. The IU contains the flight computers and critical avionics for control of the Ares I vehicle until separation with Orion. The Core Stage contains the main propulsion system including the LOX/LH2 fuel tanks, pressurization systems and feed lines to the Upper Stage J2X engine. The Upper Stage provides hydraulic thrust vector control for the J2X Engine. The Interstage is a cylindrical section that joins the FS to the Upper Stage and encloses the J2X engine until FS separation.

\section{Ares I J2X Upper Stage Engine}

The $\mathrm{J} 2 \mathrm{X}$ is a derived version of the Apollo-era J-2 engine. Design differences between $\mathrm{J} 2 \mathrm{X}$ and the original J-2 are intended to increase reliability, implement current humanrating requirements, increase performance, optimize vehicle integration, improve producibility, and overcome design obsolescence issues.
The $\mathrm{J} 2 \mathrm{X}$ engine is a gas generator cycle, using cryogenic LOX and LH2 for propellants and is designed to operate as a highly reliable, high-performance, restartable, upper stage engine. The J2X system consists of inlet ducts, gimbal subsystem, ancillary subsystem, hot gas and heat exchanger subsystem, oxidizer turbo pump, fuel turbo pump, gas generator subsystem, main injector, main combustion chamber, nozzle, nozzle extension, start subsystem, gas generator and main injector ignition subsystem, control subsystem (engine control unit, instrumentation, cables and connectors, instrumentation conditioning), propellant valves, ancillary valves, and pneumatics.

Figures 3 and 4 also shows major components of the Ares V based upon preliminary designs. Due to the immaturity of the Ares V, this paper will focus on the design and operability Ares I. It is worth noting that current lunar operations scenarios call for the Ares I \& V to be launched within 90 minutes of each other and thus emphasizing a key driver in high availability and operability [1].

\section{Historical Perspectives on The Saturn}




\section{AND SPACE SHUTTLE}

Now that the reader has been introduced to the baseline design for NASA's newest launch vehicle, let's take a quick look back at the two previous and highly successful vehicles so we can compare and contrast their operability characteristics.

\section{Saturn V-Mission and System Description}

The primary mission of the Saturn V launch vehicle was to place the Apollo spacecraft and lunar lander onto a translunar trajectory. This fundamental requirement led to the design of the largest launch vehicle ever developed. Figure 5 shows some basic characteristics of the Saturn V as well as its capabilities [6].

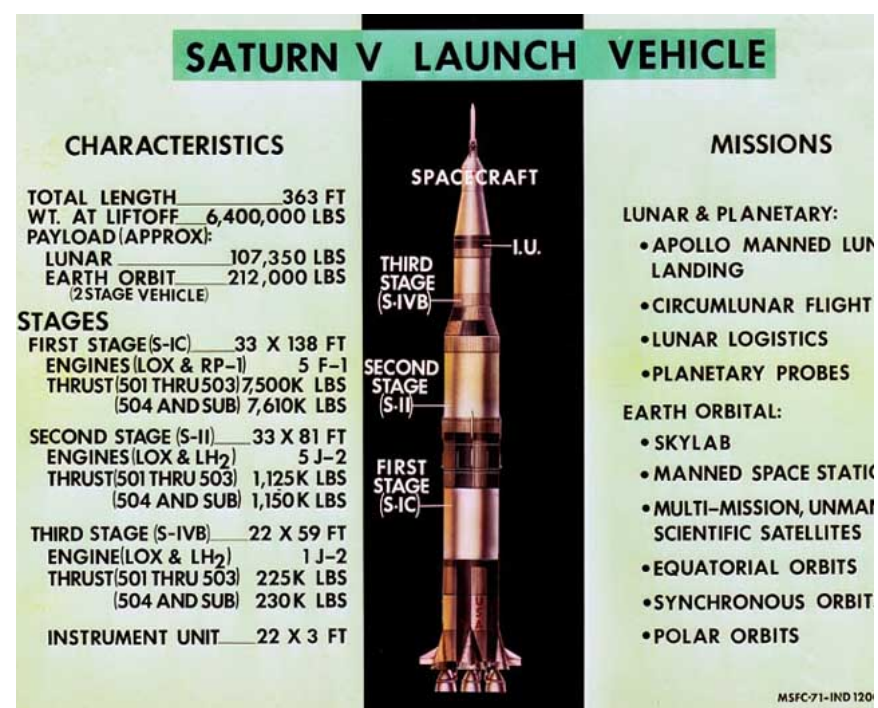

Figure 5 - Saturn V Launch Vehicle Characteristics

The Saturn vehicles were the product of a long evolutionary process stemming from initial studies in 1950 s of the Redstone and Jupiter rockets. Early conceptual studies included missiles such as Thor and Titan, and considered payloads ranging from Earth orbiting satellites to manned spacecraft such as Dynasoar, Mercury, Gemini and eventually Apollo [6].

The Saturn V evolved from the earlier Saturn vehicles as a result of the decision in 1961 to proceed with the human lunar missions. As the Apollo mission definition became clear, conceptual design studies were made, considering such parameters as structural, staging, and propulsion dynamics. Trade-offs were made in certain areas to optimize the design, based on mission requirements. The best combination of design parameters for liquid propellant vehicles resulted in low accelerations and low dynamic loads. Reliability, performance and weight were among primary factors considered in optimizing the design, operability and life cycle costs were not.

The Saturn V consisted of three propulsive stages - the S-IC first stage, S-II second stage, the S-IVB third stage; and the
Instrument Unit that contained the primary avionics and control systems. All three stages used LOX as an oxidizer. The S-IC used RP-1 for fuel, while the second and third stages used LH2. The second and third stages also used small solid-fuelled ullage motors that helped to separate the stages during ascent and to ensure that the liquid propellants were in proper position to be drawn into the pumps. The Saturn V flight history is shown in Table 1 [5].

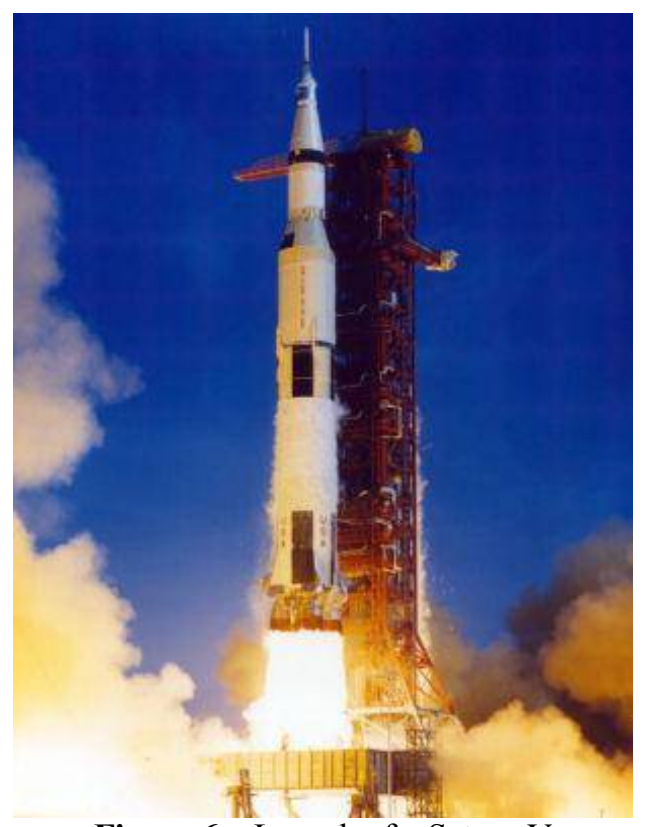

Figure 6 - Launch of a Saturn V

Table 1 - Saturn V Launch History

\begin{tabular}{|l|c|c|}
\hline \multicolumn{1}{|c|}{ Launch Date } & Launch Vehicle & Mission \\
\hline Nov 9, 1967 & SA-501 & Apollo 4 \\
\hline April 4, 1968 & SA-502 & Apollo 6 \\
\hline Dec 21, 1968 & SA-503 & Apollo 8 \\
\hline March 3, 1969 & SA-504 & Apollo 9 \\
\hline May 18, 1969 & SA-505 & Apollo 10 \\
\hline July 16, 1969 & SA-506 & Apollo 11 \\
\hline Nov 14, 1969 & SA-507 & Apollo 12 \\
\hline April 11, 1970 & SA-508 & Apollo 13 \\
\hline Jan 31, 1971 & SA-509 & Apollo 14 \\
\hline July 26, 1971 & SA-510 & Apollo 15 \\
\hline April 16, 1972 & SA-511 & Apollo 16 \\
\hline Dec 7, 1972 & SA-512 & Apollo 17 \\
\hline May 14, 1973 & SA-513 & Skylab \\
\hline
\end{tabular}

\section{S-IC First Stage}

The S-IC was built by The Boeing Company at the Michoud Assembly Facility (MAF) near New Orleans, where the Space Shuttle External Tanks are constructed today. Most of its mass, over two thousand metric tons at launch, was propellant, in this case RP-1 rocket fuel and LOX. It was 138 feet tall $(42 \mathrm{~m})$ and 33 feet $(10 \mathrm{~m})$ in diameter, and provided over 7.6 million lbs $(33,806 \mathrm{kN})$ of thrust to get 
the Saturn V through the first 33 nautical miles $(61 \mathrm{~km})$ of ascent. Five F-1 engines were arranged in a cross pattern. The center engine was fixed, while the four outer engines could be hydraulically gimbaled [6].

\section{S-II Second Stage}

The S-II stage was built by North American Aviation in California. Using LH2 and LOX, it had five J-2 engines in a cross arrangement similar to the S-IC, also using the outer engines for control. It was 81 feet tall $(24.6 \mathrm{~m})$ with a diameter of 33 feet $(10 \mathrm{~m})$, and is the largest cryogenic stage ever built. The S-II stage accelerated the Saturn V through the upper atmosphere with 1,150,000 lbs $(5,115 \mathrm{kN})$ of thrust. When loaded, more than 90 percent of the mass of the stage was propellant. Instead of having a traditional intertank structure to separate the two fuel tanks, as was done in the S-IC, the S-II used a common bulkhead that was constructed from both the top of the LOX tank and bottom of the LH2 tank. It consisted of two aluminum sheets separated by a honeycomb structure. This had to insulate against the $125^{\circ} \mathrm{F}\left(51^{\circ} \mathrm{C}\right)$ temperature difference between the two tanks. The use of a common bulkhead saved 3.6 metric tons. As a point of similarity, the Ares I will also use a common bulkhead in the Upper Stage [5].

\section{S-IVB Third Stage}

The S-IVB was built by the Douglas Aircraft Company in California. It had one J-2 engine and used the same fuel as the S-II. The S-IVB also used a common bulkhead to insulate the two tanks. It was 58 feet $(17.6 \mathrm{~m})$ tall with a diameter of 21.7 feet $(6.6 \mathrm{~m})$ and was also designed with high mass efficiency, though not quite as aggressively as the S-II. This stage was used twice during the mission: first in a 2.5 minute burn for orbit insertion and later for the translunar injection (TLI) burn, lasting about 6 minutes. Two liquid-fueled auxiliary propulsion system (APS) units mounted at the aft end of the stage were used for attitude control during the parking orbit and the trans-lunar phases of the mission. The two APSs were also used as ullage engines to help settle the fuel prior to the TLI burn. The SIVB was the only rocket stage of the Saturn V small enough to be transported by plane [6].

\section{Saturn V Instrument Unit}

The Saturn V Instrument Unit (shown in figure 7) was built by IBM in Huntsville, Alabama and rode atop the S-IVB stage. This set of avionics and inertial guidance computer controlled the operations of the rocket from just before liftoff until the S-IVB was discarded. It included guidance and telemetry systems for the rocket. By measuring the acceleration and vehicle attitude, it could calculate the position and velocity of the rocket and correct for in flight deviations.

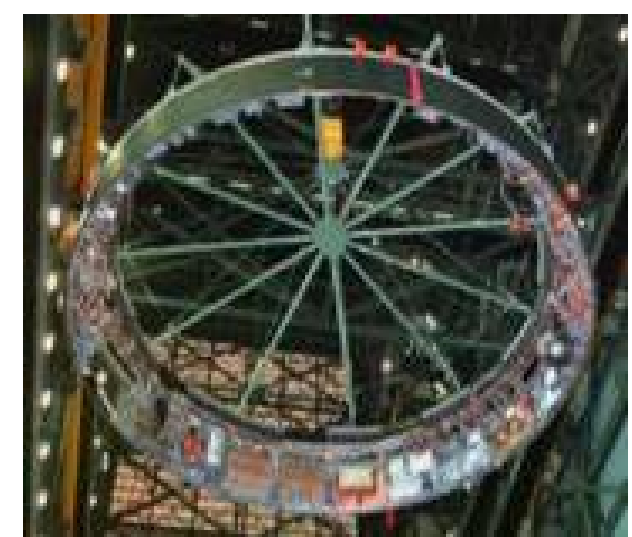

Figure 7 - The Saturn V Instrument Unit

\section{Ending the Saturn Project}

After the launch of Skylab in 1973, NASA was already transitioning to the Space Shuttle Program and there were no immediate requirements for a launch vehicle with such massive lift capability. This capability has not been equaled since. However to put the costs in perspective, from 1964 to 1973 , a total of $\$ 6.5$ billion was appropriated for the Saturn $\mathrm{V}$, with the maximum being $\$ 1.2$ billion in 1966. In 1966, NASA also received its highest budget of $\$ 4.5$ billion, about 0.5 percent of the U.S. gross domestic product at that time. Allowing for inflation this is equivalent to roughly $\$ 40$ billion in 2008. This works out at an amortized cost of approximately $\$ 3$ billion per launch. No doubt, one of the main reasons for concluding the Apollo program was cost. However, it is important to note that operability and low life cycle costs were not the highest priorities [6].

Space Shuttle - Mission and System Description

In 1969, a few months after Apollo 11, a space task group appointed by the President to study the future of space research and exploration made the recommendation that the U.S. accept the basic goal of a balanced human and robotic space program. To achieve this goal it was recommended that NASA develop new systems for space operation through a program directed toward development of a new, more affordable space transportation capability. In 1970, NASA initiated extensive engineering, design and cost studies covering a wide variety of concepts ranging from a fully reusable human rated booster and orbiter to dual strapon solid propellant rocket motors and an expendable liquid propellant tank. In-depth studies of each concept evaluated development risks and costs in relation to the operational suitability and the overall economics of the entire system. Finally in January, 1972 NASA announced it would proceed with the development of a reusable Space Shuttle system. The decision was based on information developed by studies which showed that the solid rocket system offered lower development cost and lower technical risk. In 1981 the orbiter Columbia launched the Space Shuttle era [7]. 
Space Shuttle Components

The Space Shuttle launch vehicle has three main components: the Orbiter, the External Tank (ET), and Solid Rocket Boosters (SRBs). Figure 8 shows all components at launch.

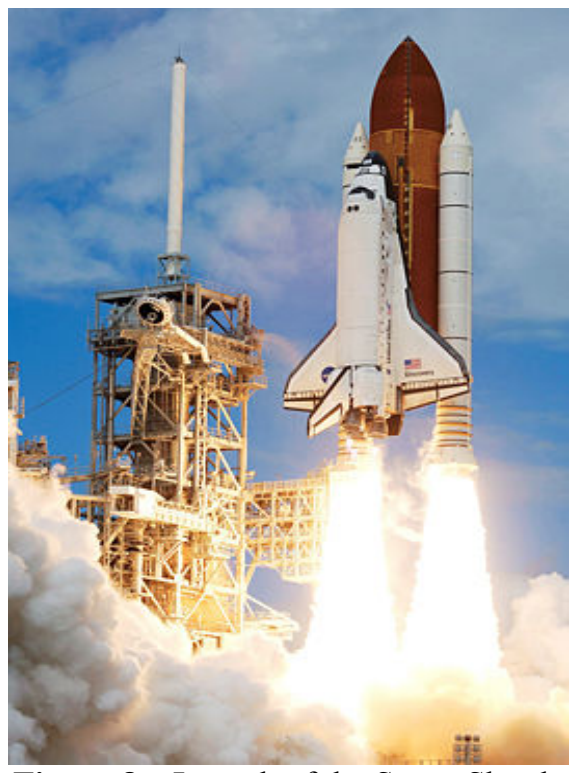

Figure 8 - Launch of the Space Shuttle

\section{Space Shuttle Orbiter}

Built by Rockwell International in California, the four original orbiter spacecraft were the Columbia, Challenger, Atlantis and Discovery. NASA named the orbiters after famous exploration sailing ships. In 1992, Endeavour was built to replace Challenger.

Table 2 - Space Shuttle Orbiter Launch Statistics

\begin{tabular}{|l|c|c|}
\hline \multicolumn{1}{|c|}{ Orbiter } & First Launch & $\begin{array}{c}\text { Number of } \\
\text { Launches }\end{array}$ \\
\hline Columbia $^{*}$ & Apr 12, 1981 & 28 \\
\hline Challenger $^{* *}$ & Apr 4, 1983 & 10 \\
\hline Discovery & Aug 30, 1984 & 35 \\
\hline Atlantis & Oct 3, 1985 & 29 \\
\hline Endeavour & May 7, 1992 & 21 \\
\hline
\end{tabular}

Columbia - Destroyed on reentry Feb 1, 2003, STS -107

${ }^{* *}$ Challenger - Destroyed on ascent, Jan 28, 1986, STS-51L

The orbiter is the crew and payload carrying unit of the Shuttle system. It is 121 feet $(37 \mathrm{~m})$ long, has a wingspan of 79 feet $(24 \mathrm{~m})$, and weighs approximately $150,000 \mathrm{lbs}$ $(68,040 \mathrm{~kg})$ without fuel. It is about the size and weight of a DC-9 commercial air transport. An orbiter can transport a payload up to $65,000 \mathrm{lbs}(29,480 \mathrm{~kg})$ into orbit. It carries its cargo in a payload bay 60 feet $(18 \mathrm{~m})$ long and 15 feet $(4.5$ $\mathrm{m}$ ) in diameter. The bay is flexible enough to provide accommodations for robotic spacecraft, large experiments, space station elements or even fully equipped scientific laboratories. The orbiter's three main liquid rocket engines each have a thrust of 470,000 lbs $(2,090 \mathrm{kN})$. During ascent they are fed propellants from the ET. The orbiters are transported before and after their missions atop a specially outfitted Boeing 747, shown in Figure 9 [8].

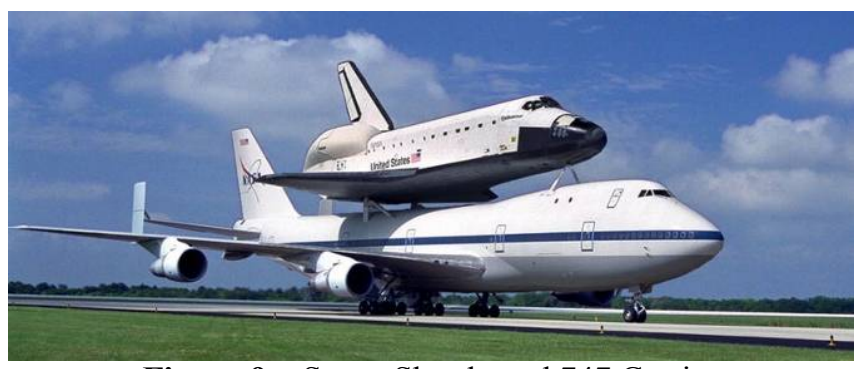

Figure 9 - Space Shuttle and 747 Carrier

Space Shuttle External Tank

Manufactured by Lockheed Martin at the Michoud Assembly Facility in Louisiana, the ET is 154 feet $(47 \mathrm{~m})$ long and 28.6 feet $(8.7 \mathrm{~m})$ in diameter. After manufacturing is completed, the ET is transported by barge from Louisiana to Florida. At lift off, the tank holds 1,550,000 lbs (703 mT) of LH2 and LOX. The hydrogen and oxygen are in separate pressurized compartments of the tank. The ET does not use a common bulkhead design. The ET is the only part of the shuttle system that is not reusable.

\section{Space Shuttle Solid Rocket Boosters}

Manufactured in Utah by ATK, the shuttle SRBs are the pair of large solid rockets used by the Space Shuttle during the first two minutes of powered flight. They are located on either side of the ET. Each SRB produces 1.8 times more liftoff thrust than a single Saturn V F-1 engine with a sea level thrust of 2,600,000 lbs $(11,565 \mathrm{kN})$. The SRBs are the largest solid-fuel rocket motors ever flown, and the first to be used for primary propulsion on human spaceflight missions. The spent SRBs are recovered from the ocean, refurbished, reloaded with propellant, and reused for several missions. The SRB segments are transported between Utah and Florida by specially designed rail cars.

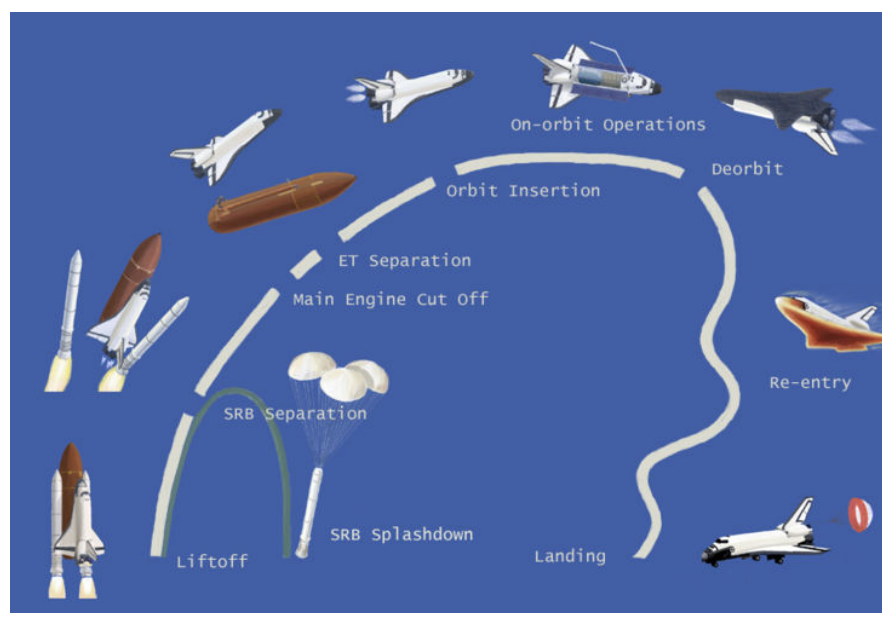

Figure 10 - Space Shuttle Mission Profile 


\section{What is Operability ANd How Do You DESIGN IT INTO A LAUNCH VEHICLE?}

There are many definitions of operability used within the aerospace industry and it is important to scope the general definition of this term. The Constellation Program defines operability as "the ability of a system to be operated for a specified duration under specified operating conditions at a specified capability with specified resources." The key components of which are Duration, Operating Conditions, Capability, and Resources are described below [2]. It is a complicated definition that does not lend itself to easy interpretation. However, if taken in parts, the implications of requirements and design decisions start to become clear.

\section{Duration}

Duration is the period of time or number of cycles the system can be made to perform its intended function - this may be minutes, hours, days, or longer; it can also be the number of sorties; or number of openings/closings. Duration is a function of the system capability, operating conditions, and resources. This makes system duration a dependent variable and, because it is dependent on operating conditions, is uncontrollable. An example of duration for Ares is the pre-launch countdown phase. To maximize the operability of the vehicle it is desirable to minimize the countdown duration. However, due to constraints such as propellant fill rates, safety procedures and many others, the duration of the countdown becomes dependant on how the various systems are designed. Realizing this early in the design process and striving to maximize key operability factors can have a significant impact on the design.

\section{Operating Conditions}

Operating conditions describe the environments in which the system performs its intended function. These are also independent and uncontrollable variables. A system is designed with the capability to function within a range of conditions. Variations in the operating conditions determine the resource consumption rates and induce failures and thereby determine duration. Launch vehicle operating conditions include temperature, pressure, humidity, winds, facility and safety constraints just to name a few. Internal conditions must also be considered and include combustion temperatures and pressures, heat generated by electronics, or physical stresses placed on crew members. For Ares, a key condition that has a huge impact on operability is the integration facility and its proximity to the launch pad. For maximum operability, a launch vehicle of this type should remain inside its integration facility for as long as possible prior to launch for protection and servicing. It is also beneficial to have a rapid transportation method between the facility and the launch pad. Ares will use heritage integration facilities like the Vehicle Assembly Building (VAB) and crawler transporter from the Apollo and the Space Shuttle programs. The 8-hour roll-out period from the $\mathrm{VAB}$ to the launch pad is a significant design driver for Ares with non-trivial impacts to operability. It drives a multitude of logistical decisions from how many launch platforms are needed, to ground support equipment resources and vehicle service points.

\section{Capability}

The capability of a system for its intended function measures how well it accomplishes the assigned task - as a result of the hardware and software configurations of the vehicle and supporting infrastructure. This is an independent and controllable variable and it determines how effectively the system performs its function. Once the system is deployed, its capability is considered to be variable only through failure or modification. In the countdown phase, the Ares launch vehicle capability is measured against number of attempts versus successful launches. For this category, system reliability is key - for ground as well as on-board systems. As with every launch vehicle, there is an enormous desire to minimize the number of launch scrubs, which are very expensive. For Constellation, this becomes even more critical for the lunar campaign due to the short time planned between Ares I and Ares V launches.

\section{Resources}

Resources are the elements necessary to sustain performance of the intended system function. For a launch vehicle they include propellants, gases, electrical power, unique facilities, human mental and physical effort, as well as budgets just to name a few. These quantities may be fixed or varied. Resources are independent and controllable variables that result in another measure of system efficiency. For Ares, a great deal of attention has been paid to areas of the design that require expensive, limited and/or environmentally hazardous resources. In some cases performance has dictated use of a costly consumable, like cryogenic helium, but these decisions are approved only after a great deal of scrutiny and trade studies exhaust all other options.

\section{Managing Operability}

Project managers have defined plans that drive operability and affordability into both the design and management decisions. In simplified terms, they infuse operability on a daily basis by specifying goals and allow engineers to assess various design options. Management tracks the results as well as what actions are necessary for implementing the options. The culmination of these activities and processes provide a prediction of the outcome of current design implementations and measure their anticipated affect on steady-state life cycle costs [4].

A primary operability goal is to significantly reduce annual recurring cost of the Ares I vehicle beginning in 2015 with the current baseline of two flights per year. This represents a recurring annual cost reduction of 50 percent from the Space Shuttle Program. This goal is driven by financial constraint NASA must carry the production and operations costs for the Ares I and also have enough resources available to continue the development of additional components such as the Ares V. As a result, it is imperative to establish targets 
for the cost of operations and actively monitor and manage these. Another goal is to significantly increase probability of launch by 50 percent over that of the Space Shuttle [2]. The second is also driven by budget, but even more by the tight launch window constraints imposed by the Ares I-Ares V lunar launch campaigns.

Another set of Constellation operability goals are designated as "stretch goals." These are aggressive constraints upon the entire Program (i.e. Ares, Orion and ground elements) and usually require discontinuous changes in design or operational concepts. They are selected such that the final systems can exhibit dramatic reductions in operational life cycle cost and/or improve system operability. A recent example includes examining a flight rate of 10 Ares I/Ares $\mathrm{V}$ combinations per year! In the end, operability will be the by-product of designing the vehicle for successful missions while concurrently optimizing for greater availability and process efficiencies, maximizing utilization of assets, and reducing life cycle cost.

Leading up to the Ares I Preliminary Design Review in the summer of 2008, great strides were made towards meeting requirements and operability goals. After the review was complete, operability requirements analysis and proposed design changes were documented in an operability assessment table similar to Table 3 below.

Table 3 - Ares I Operability Assessment Table (example)

\begin{tabular}{|l|l|}
\hline \multicolumn{1}{|c|}{$\begin{array}{c}\text { Operability } \\
\text { Impacts }\end{array}$} & \multicolumn{1}{c|}{ Status } \\
\hline $\begin{array}{l}\text { FS Off-Line } \\
\text { Options Prior to } \\
\text { VAB Integration }\end{array}$ & $\begin{array}{l}\text { New launch mount approved per FS } \\
\text { nozzle extension redesign }\end{array}$ \\
\hline $\begin{array}{l}\text { Common Battery } \\
\text { Use }\end{array}$ & $\begin{array}{l}\text { Action to implement use of common } \\
\text { battery types across the whole } \\
\text { vehicle, wherever possible }\end{array}$ \\
\hline $\begin{array}{l}\text { FS Forward Skirt } \\
\text { Thermal Analysis }\end{array}$ & $\begin{array}{l}\text { Current analysis shows purge not } \\
\text { required in forward skirt }\end{array}$ \\
\hline $\begin{array}{l}\text { Manual Steering } \\
\text { During Ascent }\end{array}$ & $\begin{array}{l}\text { Increase in system complexity, test } \\
\text { and training requirements were } \\
\text { deemed acceptable due to increased } \\
\text { operational flexibility. }\end{array}$ \\
\hline $\begin{array}{l}\text { Thrust Oscillation } \\
\text { Mitigation }\end{array}$ & $\begin{array}{l}\text { Design analysis to determine cause } \\
\text { and options to mitigate first stage } \\
\text { Options }\end{array}$ \\
\hline
\end{tabular}

\section{Comparisons OF LAUnCh Operations- SATURN V, Space Shuttle \& Ares I}

It is interesting and very useful to directly compare the Saturn V, Shuttle and Ares vehicles through the phases of manufacturing, integration and finally flight operations. By comparing and contrasting the operational concepts to their operational realities, we discover if their design goals were achieved or, as in some cases, turned into operational liabilities.

\section{Manufacturing and Transportation}

As stated previously, the Saturn V stages were built in separate facilities, far from the launch site. The first two stages were so large that the only way to transport them was by water. In the case of the S-II stage, it traveled from California to Florida via the Panama Canal; quite a great distance and at significant risk considering weather and security for such a critical piece of flight hardware. The third stage and IU were carried by oversized transport aircraft. Manufacturing the elements closer to the launch site would have reduced physical risk as well as transportation time/cost. Another option would have been to transport the elements in smaller pieces for integration at the launch site. Other factors such as existing manufacturing capability and/or politics may have influenced location choices at the time. It is important to note, however, that operability and cost control were not primary design objectives for Saturn.

The Space Shuttle Program heeded these logistical lessons, as only the ET is transported by water over the relatively short distance from Louisiana to Florida through the Gulf of Mexico and Intra-Coastal Waterway. However, this still exposes the ET to potentially extreme weather, especially during hurricane season. The SRB segments are transported between Florida and Utah via railcar with relatively simple yet effective security and protection from the elements. Note the forward and aft SRB segments remain at the Kennedy Space Center (KSC) for refurbishment to minimize transport costs. Orbiters are returned from remote landing sites back to KSC for their next launch via the 747 shuttle carrier aircraft (SCA). This is a secure method of transportation, however a great deal of Ground Support Equipment (GSE) is needed to mate and demate the orbiters from the SCA so every effort is made to land at KSC [9].

Ares I will use a hybrid of both transportation methods due in part to design and budget constraints to reuse existing facilities and GSE. The Upper Stage will follow the Saturn heritage of shipping a fully constructed stage by barge from MAF. The FS segments will be manufactured in Utah and transported using similar processes as the Shuttle SRBs.

\section{Vehicle Integration and Ground Processing}

On arrival at the launch site, each Saturn V stage was checked out in a horizontal position before being moved to a vertical position in the VAB. NASA also constructed large spool-shaped structures that could substitute for a behindschedule stage until its arrival. These spools had the same height and mass and contained the same electrical connections as the actual stages. Once fully integrated to its mobile launch platform and launch tower in the VAB, the Saturn was moved out to the launch pad by an immense tracked vehicle called the crawler. It carried the launch platform, and vehicle 3 miles $(4.8 \mathrm{~km})$ out to the launch pad in approximately 8 hours. See Figure 11 . 


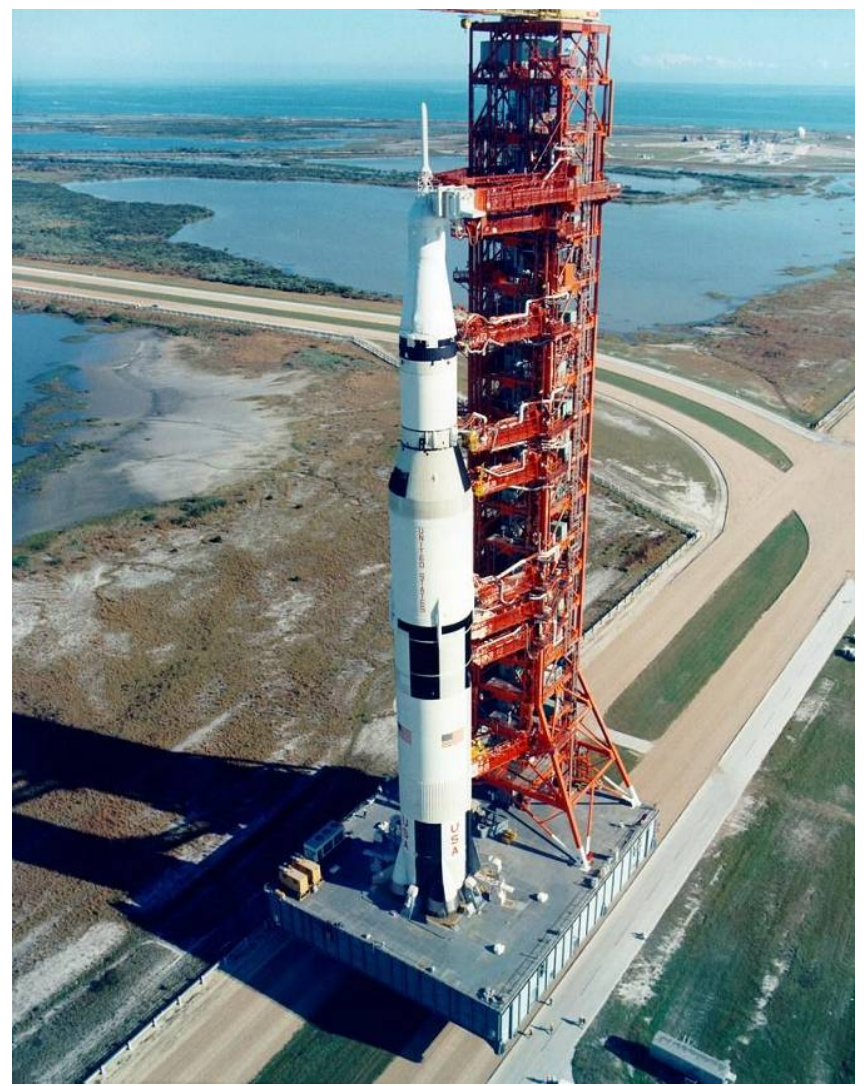

Figure 11 - Saturn V and Launch Tower Roll Out

Like Saturn, Space Shuttle integration occurs inside the VAB. The SRB segments are transferred from nearby checkout facilities, hoisted onto a mobile launcher platform and stacked to form two complete SRBs. Then the ET is lifted and mated to the two SRBs. Finally, the orbiter is towed from the orbiter processing facility to the VAB, raised to a vertical position and mated to the ET. When assembly and checkout is complete, the crawler-transporter picks up the platform and assembled shuttle vehicle and carries them to the launch pad. The crawler used by the Space Shuttle is the same as that was used for Saturn. Note that the Shuttle launch tower is a fixed structure at the launch pad and not on the mobile platform. This architecture was chosen among other reasons, to allow for large payload installation or change out at the launch pad. It has the drawback of continuous exposure to weather [9].

Ares I integration and launch preparation will include a mix of Saturn and Shuttle processes. The FS will be stacked on a mobile platform and launch tower in segments inside the VAB, nearly identical fashion to Shuttle. Next the fully integrated Upper Stage will be lifted and mated on top. Finally the Orion spacecraft will be mounted on top. Constellation concepts call for nearly all integration tests to be performed inside the VAB. To minimize exposure to weather, the vehicle and launch tower will be taken to the launch pad only a few days before launch.

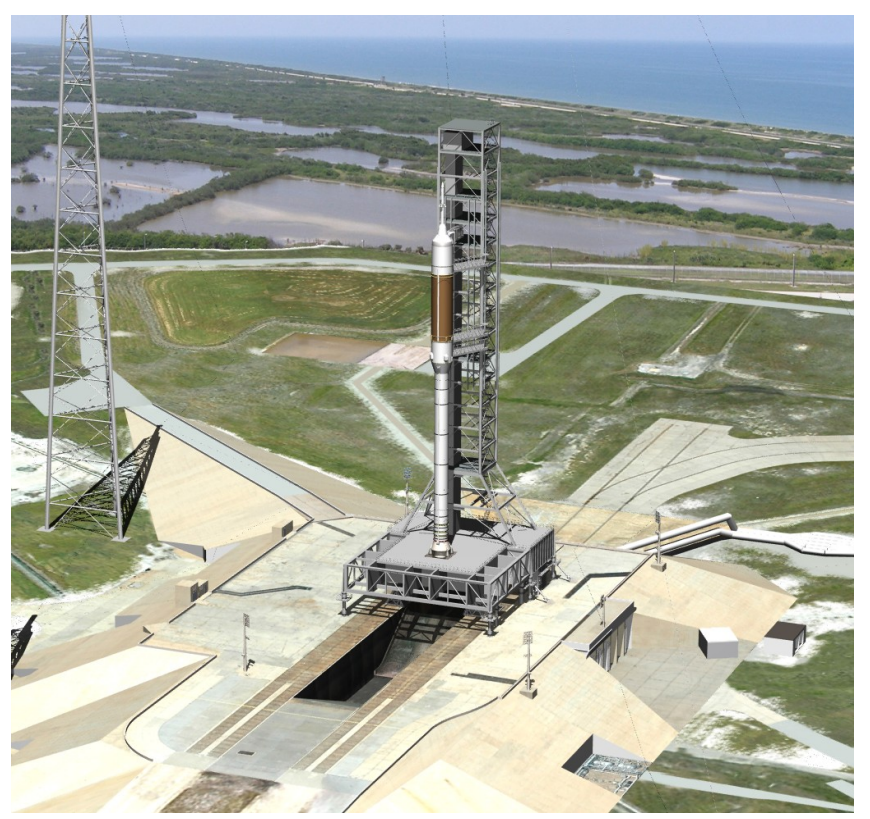

Figure 12 - Artist Concept of the Ares I on the Launch Pad

\section{Countdown, Launch and Ascent}

Approximately four days before launch, the Saturn V countdown began and the vehicle was subjected to final checkout and servicing operations. The final phase of the countdown started approximately nine hours prior to liftoff. During this phase, the cryogenics tanks were conditioned, loaded and pressurized. At T-9 seconds, the S-IC ignition command was given. At T-0 seconds, the launch commit signal was given, causing the hold down arm to retract.

At launch, the Saturn V rose nearly vertically from the pad, for approximately 450 feet $(137 \mathrm{~m})$, to clear the tower. During this period, a yaw maneuver was executed to provide tower clearance in the event of adverse wind conditions or engine failure. After clearing the tower, another maneuver was initiated to achieve the proper flight attitude. Maximum dynamic pressure was encountered at approximately 1 minute 24 seconds into flight. The S-IC center engine cutoff was commanded at 2 minutes to limit the acceleration to $4 \mathrm{G}$ 's. At approximately 3 minutes the first stage was empty of propellants and jettisoned. During this period, ullage rockets were fired to seat the S-II propellant and the S-IC/S-II separation occurred. The S-II aft interstage and Apollo launch escape tower were jettisoned 30 seconds later. At 9 minutes into flight, the second stage was jettisoned and the S-IVB inserted the vehicle into a 100 -nautical mile $(185 \mathrm{~km})$ circular parking orbit [5].

Space Shuttle launch operations are controlled from the same Launch Control Center (LCC) used by Saturn. The countdown begins approximately 43 hours before the launch. ET tanking operations are begun in parallel with the activation of various vehicle systems. The final 10 hours of the count include a final mission software update, completion of propellant system purges, loading of LH2 and LOX into the ET. At T-9 minutes, the automated ground 
launch sequencers takes over and from this point, all functions in the count are under computer control. At T-10 seconds, commands are issued for Space Shuttle Main Engine (SSME) ignition. At T-0 the ignition commands are issued to the two SRBs and the vehicle lifts off.

After clearing the launch tower, the shuttle executes a pitch and roll maneuver to align with the desired azimuth. Shortly after launch, the SSMEs are throttled down to minimize aerodynamic loads until maximum dynamic pressure has passed, about 60 seconds into flight. At approximately 2 minutes, the SRBs have exhausted their propellant and are jettisoned. They subsequently parachute back to the Atlantic Ocean, about 150 miles $(270 \mathrm{~km})$ from KSC, and are recovered to be reused. The orbiter and ET continue their climb to orbit. SSME cutoff occurs about 8 minutes, 40 seconds after launch. The ET is jettisoned and reenters over the Indian Ocean. The orbiter then adjusts its final orbit with orbital maneuvering engines and continues on with its mission.

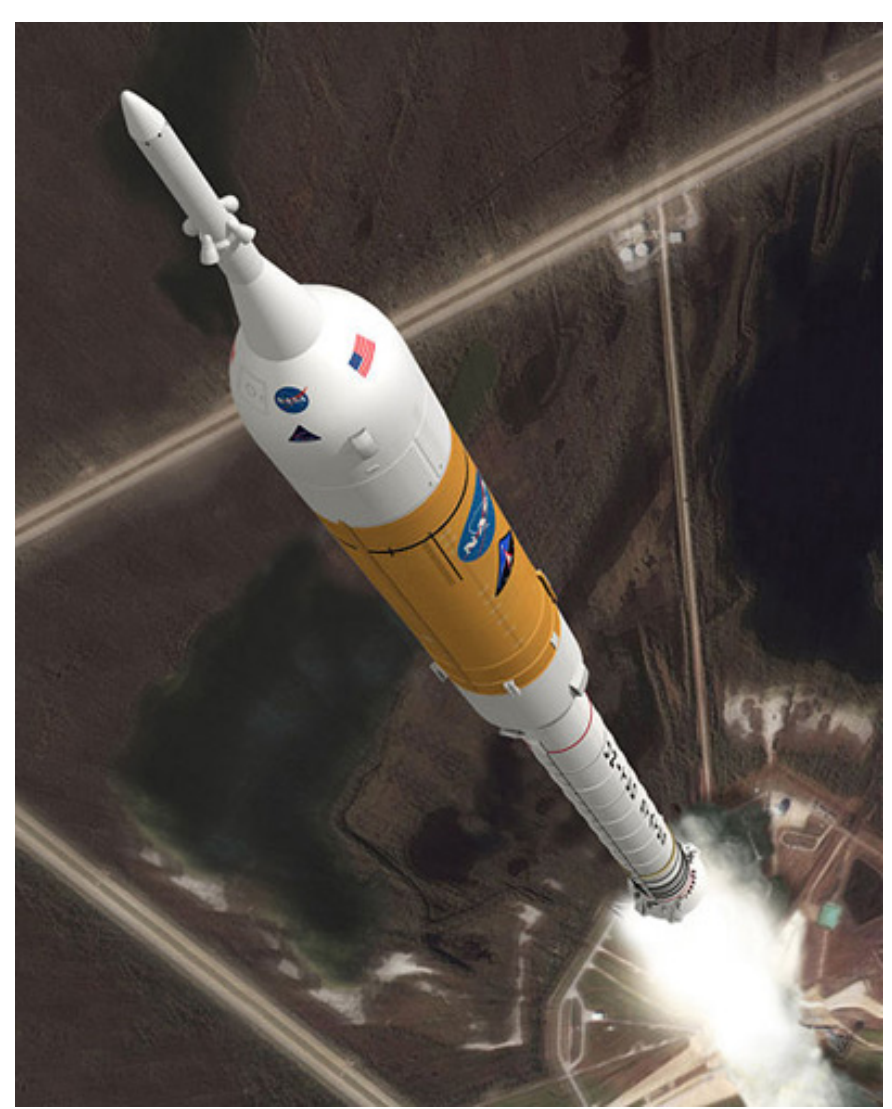

Figure 13 - Artist Concept of an Ares I Launch

Ares I pre-launch and launch control activities will also be conducted from the KSC LCC. The Ares I will arrive at the launch pad 84 hours prior to launch. At T-6 hours, Upper Stage cryo-loading starts. The crew will be loaded into the Orion two hours before launch. Ares will be transferred to internal power at T-60 seconds and at T-0 the FS ignition command is issued. See Figure 13.
Due to its high thrust-to-weight early in flight, the Ares I quickly clears the launch tower. It will climb vertically for approximately 350 feet $(105 \mathrm{~m})$ then begin a roll and pitch maneuver to align with the launch azimuth. Maximum dynamic pressure occurs about 60 seconds into flight. The FS jettison occurs 120 seconds after launch after which, it parachutes down to the Atlantic Ocean, to be recovered.

After the FS is clear, the J2X engine start command is issued and it achieves 90 percent thrust in approximately 3 seconds. The Orion launch abort system is jettisoned approximately 30 seconds after J2X start. The J2X burn lasts for nearly 9 minutes placing the Orion in its initial orbit. The Orion/Upper Stage separation sequence occurs and the Upper Stage reenters over the Indian Ocean.

\section{OPERATIONS \& OPERABILITY IMPROVEMENTS FOR FUTURE LAUNCH VEHICLES}

\section{Lower Recurring Cost by Selective Component Reuse}

As stated above, one of the enabling tenets of the Ares Project is the emphasis being put on minimizing recurring costs. The Space Shuttle Program made a deliberate effort to reuse flight hardware wherever possible with the expectation that this would lead to a significant reduction in recurring costs. This made sense as in the previous program every Saturn V was new and certified for flight at a very high cost. In fact the high costs of refurbishment and recertification, particularly for the orbiter, has shown that reuse does not explicitly lead to lower recurring costs. With over 120 Space Shuttle flights, economics has shown that often it is less expensive and safer to build launch vehicles for only one flight, especially for components that are subjected to the high dynamic stresses of ascent and reentry.

Ares I is splitting the difference between Saturn V and the Shuttle. The Upper Stage structure is being optimized to take the stress of the required testing cycles and one flight only. The J2X engine is being designed for only one launch, thus avoiding the refurbishment design impacts built into SSMEs. The FS will be reusable, as experience from the Shuttle Program has shown that SRB segments can be cost effectively refurbished. An Ares trade study considered expendable solids to increase performance, but designs for more rugged, reusable segments offered significant longterm cost savings.

Reducing Processing and Maintenance at the Launch Site Another aspect of operability improvements that Ares is aiming for is through the reduction of lengthy and expensive unplanned maintenance activities at the launch site. Shuttle Program experience has shown that when specialized and invasive procedures are needed to perform unplanned repairs, they are killers to cost and schedule. Prime examples have been ET cutoff sensor repairs and orbiter wiring maintenance. Detailed logistics studies have shown that where possible, these types of procedures should be 
done at manufacturing sites to reduce cost and the impact to integration facilities and schedules. For example, if an Ares Upper Stage requires invasive and unplanned maintenance after arriving at $\mathrm{KSC}$, it will be shipped back to the manufacturing site and the next production Upper Stage will be used in its place. This will result in reducing the recurring refurbishment testing now done in the course of Space Shuttle launch processing thus translating into higher operability at less total cost.

\section{Maximizing Availability Through Reliability and Logistics}

The requirements for launch availability state that the Ares I must have a probability of at least 98 percent successful launch after the start of countdown. The Ares Project will meet this requirement though several strategies.

First and foremost in the Ares I design is a reliance on highly reliable components. This is critical when launching crewed and high value assets to space. However, the trade study impacts between using extremely reliable components and a reduction of system redundancy is not obvious. Historically in the development of crewed launch vehicles, there is a fundamental debate on how reliable a system must be, or how many "9's" to have after the decimal place when calculating statistical system reliability. In the Ares I design, this discussion was born out of a decision of avionics redundancy. Initially, four sets of duplicate flight computers and critical flight control strings were base lined. However after the statistical analysis of the system reliability was calculated, it was found that a system of 3 redundant flight computers was essentially just as reliable.

Ares I launch availability is also increased due to a requirement for simpler and more streamlined launch pad operations. Following the lead of successful launch vehicles like the Atlas V and Delta IV, Ares will rely less on pad maintenance capability than in the Shuttle or even Apollo programs. This in turn will lead to a more efficient launch pad flow and smaller logistical footprint at the launch site [10].

\section{Inherently Safer Launch Vehicle Design}

Finally, much has already been written about how the Ares I/Orion in-line design increases crew safety during countdown and ascent. Obviously the Orion crew capsule, by being at the top of the integrated stack, has less chance of being damaged by debris as well as a better chance of launch abort system succeeding in the event of a failure. Not so obvious however is the increase in operability by directly removing hazards like those that led to the Challenger and Columbia disasters.

\section{CONCLUSIONS}

Today's Space Shuttle launch operations are complex, timeconsuming and require a great deal of hands-on labor, which are results of decisions made early in both the Saturn and Shuttle Programs. To be fair, long term life cycle cost was not a design driver for Saturn because of the high priority to land men on the Moon before 1970. The Shuttle Program started to attack operability, but in hind-sight, may have emphasized too much on reusability. The Constellation Program recognizes for sustainable exploration, a balance between performance, reusability and operability is essential.

The objective of this paper was to identify how launch vehicle operability can be significantly increased in the design process. Developing an operable and cost effective launch vehicle demands an innovative approach to developing systems. The Ares Project has studied many aspects from previous and current launch vehicle programs to design a more operable and cost effective human rated launch vehicle. Specifically, key findings in this paper are 1) Reusability doesn't automatically mean reduced production cost; 2) Do as much integration and unplanned maintenance at the fabrication facilities; and 3) Close proximity and efficient transportation between the integration facility and launch pad are essential for high availability.

By carefully analyzing and reanalyzing preliminary concepts, system requirements and operability goals early in the design process, the final system can benefit greatly. Making a conscious effort to consider the "illities" on the same level as performance and other traditional "hard-core" engineering disciplines, will enable the Constellation Program to design, build and afford all the elements required for a truly balanced and sustained space exploration program for decades to come. 


\section{REFERENCES}

[1] Best, J.; Chavers, D.; Richardson, L; Cruzen, C.; "Operational Concept for the NASA Constellation Program's Ares I Crew Launch Vehicle", AIAA Space Ops Conference, Heidelberg, Germany, May 2008.

[2] Singer, C.; Dumbacher, D.; Lyles, G.; Onken, J.; "NASA's Ares I and Ares V Launch Vehicles - Effective Space Operations Through Efficient Ground Operations", AIAA Space Ops Conference, Heidelberg, Germany, May 2008.

[3] Rhatigan, J. L.; Thomas, L.D.; J. L.; Hanley, J. M.; "Formulation of NASA's Constellation Program", International Aerospace Conference Paper IAC-07B3.1.06; 2007.

[4] Rhatigan, J. L.; Hanley, J. M.; Geyer, M. S.; "NASA's Constellation Program: From Concept to Reality", International Aerospace Conference Paper IAC-08B3.1.07; 2008 .

[5] Saturn V Flight Manual SA 507 - MSFC MAN 507 August 1969.

[6] Bilstein, R. E.; "Stages to Saturn - A Technological History of the Apollo/Saturn Launch Vehicles", NASASP 4206, 1980.

[7] Jenkins, D. R.; "Space Shuttle: The History of the National Space Transportation System"; Voyageur Press, 2007.

[8] NASA Space Shuttle News Release, 1981.

[9] Heppenheimer, T. A.; "The Space Shuttle Decision: NASA's Search for a Reusable Space Vehicle", NASASP 4221, 1999.

[10] Simpkins P.; Littlefield A.; Schultz, L.; "Infusing Operability: KSC Launch Experience Helps Shape New Vehicle Design", NASA Ask Magazine, Spring 2008.

\section{BIOGRAPHY}

Craig A. Cruzen is employed by NASA's Marshall Space

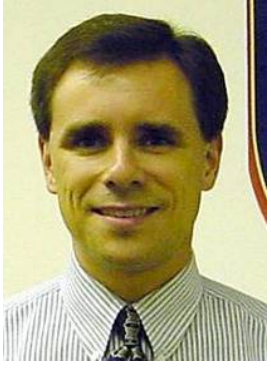

Flight Center in Huntsville, Alabama., in the Operations Directors Office. Mr. Cruzen is leading a team that is developing flight operations requirements and processes for the Ares launch vehicles. Prior to joining the Constellation Program, Mr. Cruzen served as an International Space Station (ISS) Payload
Operations Director where he led the ground control team in performing ISS science operations. Prior to joining the payload operations team, Mr. Cruzen was a guidance and navigation systems engineer where he worked on the Space Shuttle program, NASA's Automated Rendezvous and Capture project as well as other vehicle development programs. He holds a Bachelors degree in Aerospace Engineering ('92) from the University of Michigan in Ann Arbor. Mr. Cruzen and his wife Cassandra have two sons; Kyle and Collin. Mr. Cruzen is also a Flight Instructor at Redstone Arsenal in Huntsville.

Dr. Greg Chavers is a team lead in the Mission Operations

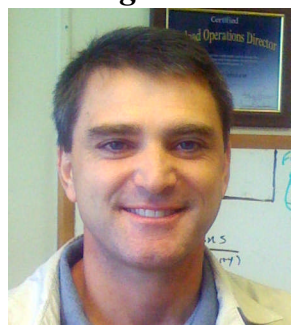
Laboratory at NASA's Marshall Space Flight Center. From 19992006 Dr. Chavers was the Principal Investigator for an advanced plasma propulsion experiment to verify detachment from a magnetic nozzle. From 1993-1999, he was a test engineer for the Chandra X-ray Astrophysics Facility. He began his career at NASA in 1991 supporting ISS design and the Hubble Space Telescope maintenance mission. Dr. Chavers earned his Bachelors degree in Aerospace Engineering from Auburn University ('90). He received a Masters degree in Physics from the University of Alabama in Huntsville (UAH) ('98) and his Ph.D. in Physics from UAH ('03). Dr. Chavers and his wife Denise have three children; Marissa, Maleiha, and Dustin.

Gerald (Jerry) Wittenstein is CEO of International Space Systems, Inc (ISSI). His experience base spans Saturn thru

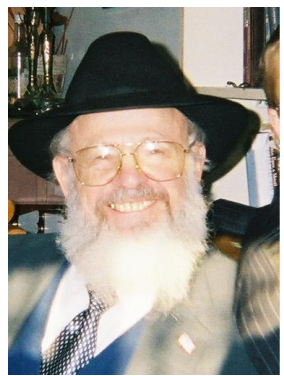
Space Shuttle-Space Lab. As an employee of MSFC from 1961-1986, he served as chief of the Flight Mechanics and the Orbital Analysis Branches. His duties included integration of navigation systems for the Saturn V Instrument Unit, and he was responsible for the guidance systems pre-settings. $\mathrm{He}$ assisted Spacelab design and then in on-orbit payload operations both as an Orbit Analysis Engineer and a Payload Activity Planner. His current work on Ares includes support of Ares flight operations requirements development and performance analysis. He received a Bachelors degree in physics from Birmingham Southern ('61); he also received Masters Degrees from UAH in Physics ('70) and in Management ('75). Jerry and his wife Carol have four children; Deborah, Arnold, Mordachai, and Ron, as well as a parcel of grandchildren. 


\section{ACKNOWLEDGEMENTS}

The authors would like to acknowledge and thank the following groups.

- The astronauts who live and work in space and risk their lives every day to contribute to the success of space exploration for all mankind;

- The NASA engineers, scientists and support staff who commit their careers to designing and flying exploration systems and spacecraft to push all boundaries and in turn improve our way of life on Earth;

- Our colleges and reviewers who contributed to the development of this paper: Clive Arlington, Mark Emery, Tim Horvath, David Scott, Raymond Shaughnessy, John Wade and Carol Wittenstein. 
Operational Considerations and Comparisons NasA of the Saturn V, Space Shuttle and Ares Launch Vehicles

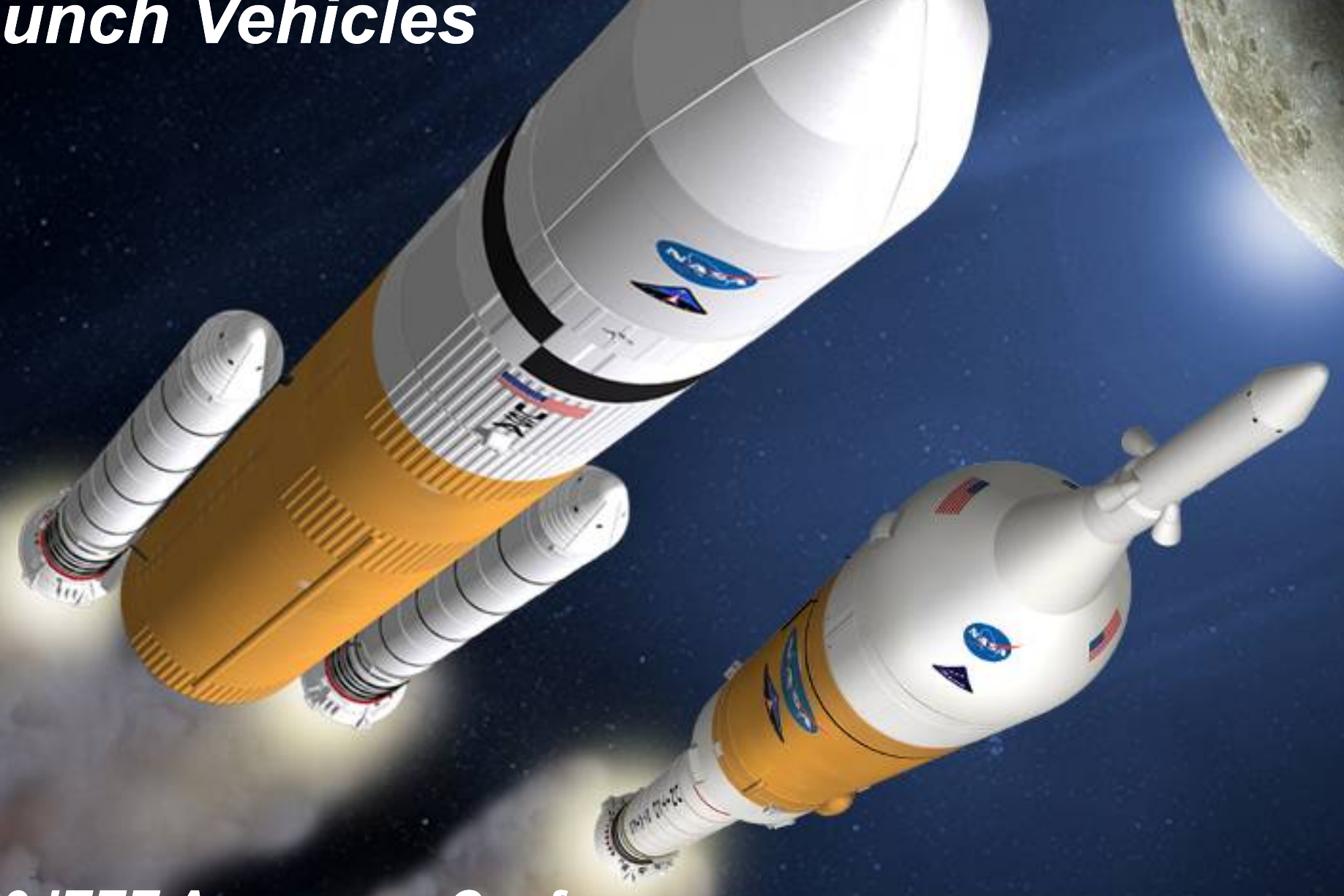

2009 IEEE Aerospace Conference

Big Sky, Montana March 9, 2009 Marshall Space Flight Center

Craig Cruzen NASA 


\section{Paper Authors}

\section{Craig Cruzen \\ Marshall Space Flight Center \\ Huntsville, AL 35812 \\ 256-544-8658 \\ craig.cruzen@nasa.gov}

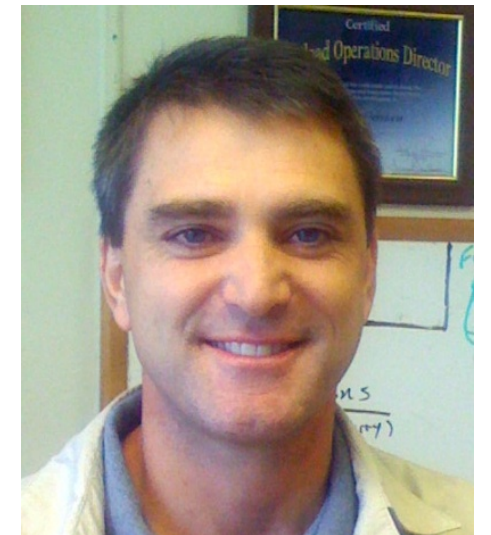

Dr. Greg Chavers

Marshall Space Flight Center

Huntsville, AL 35812

256-544-5541

greg.chavers@nasa.gov

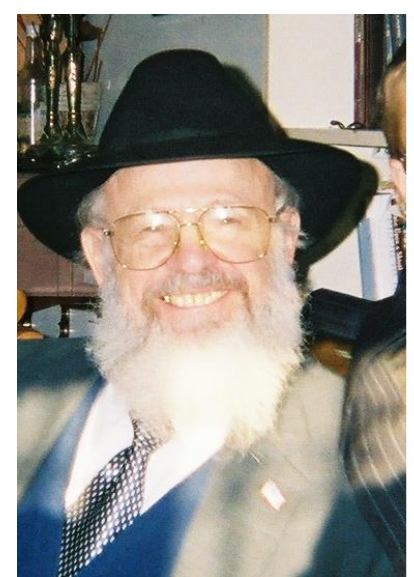

Jerry Wittenstein

International Space Systems, Inc.

Huntsville, AL 35812

256-544-2047

jerry.wittenstein-1@nasa.gov 


\section{NASA's Plan for Space Exploration}

- Safely fly the Space Shuttle and complete the International Space Station

- Develop and fly the Orion crew exploration vehicle no later than 2015

- Return to the moon no later than 2020

- Promote international and commercial participation in exploration

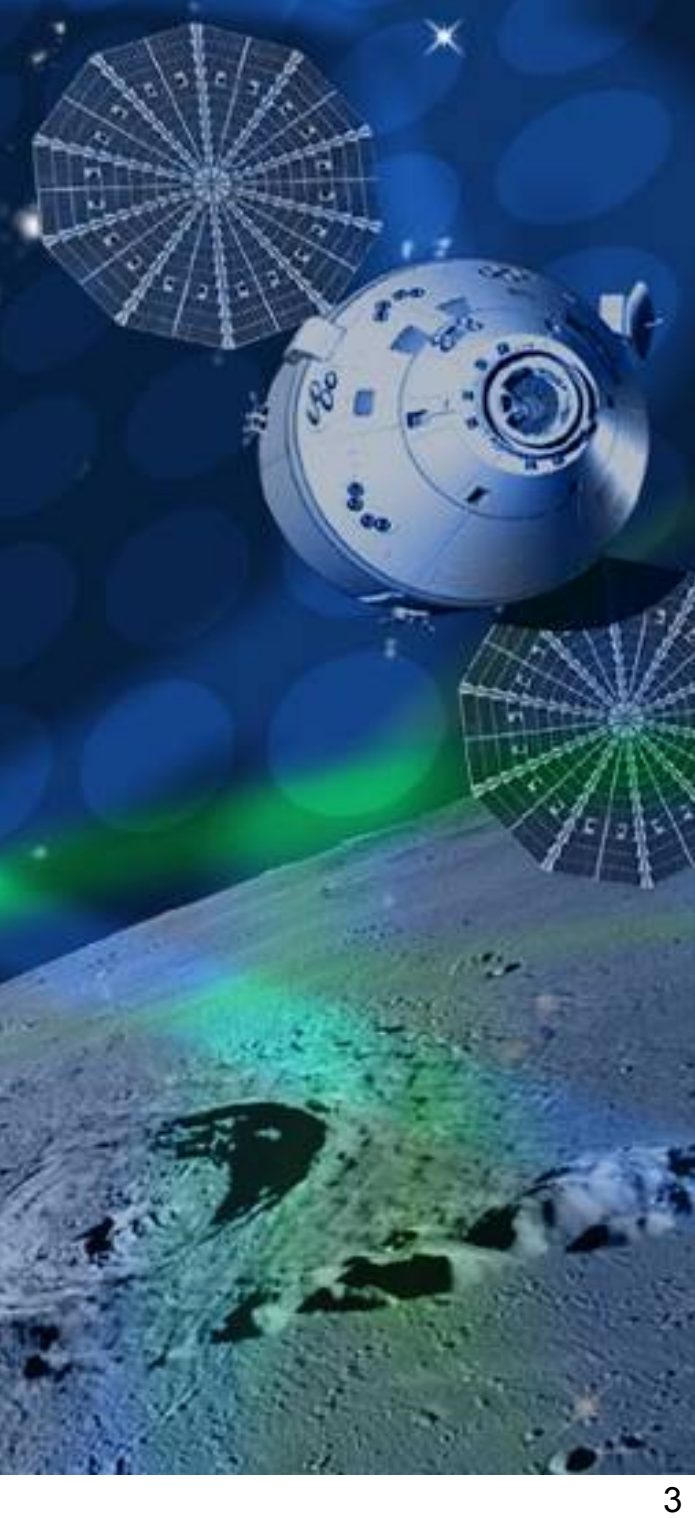




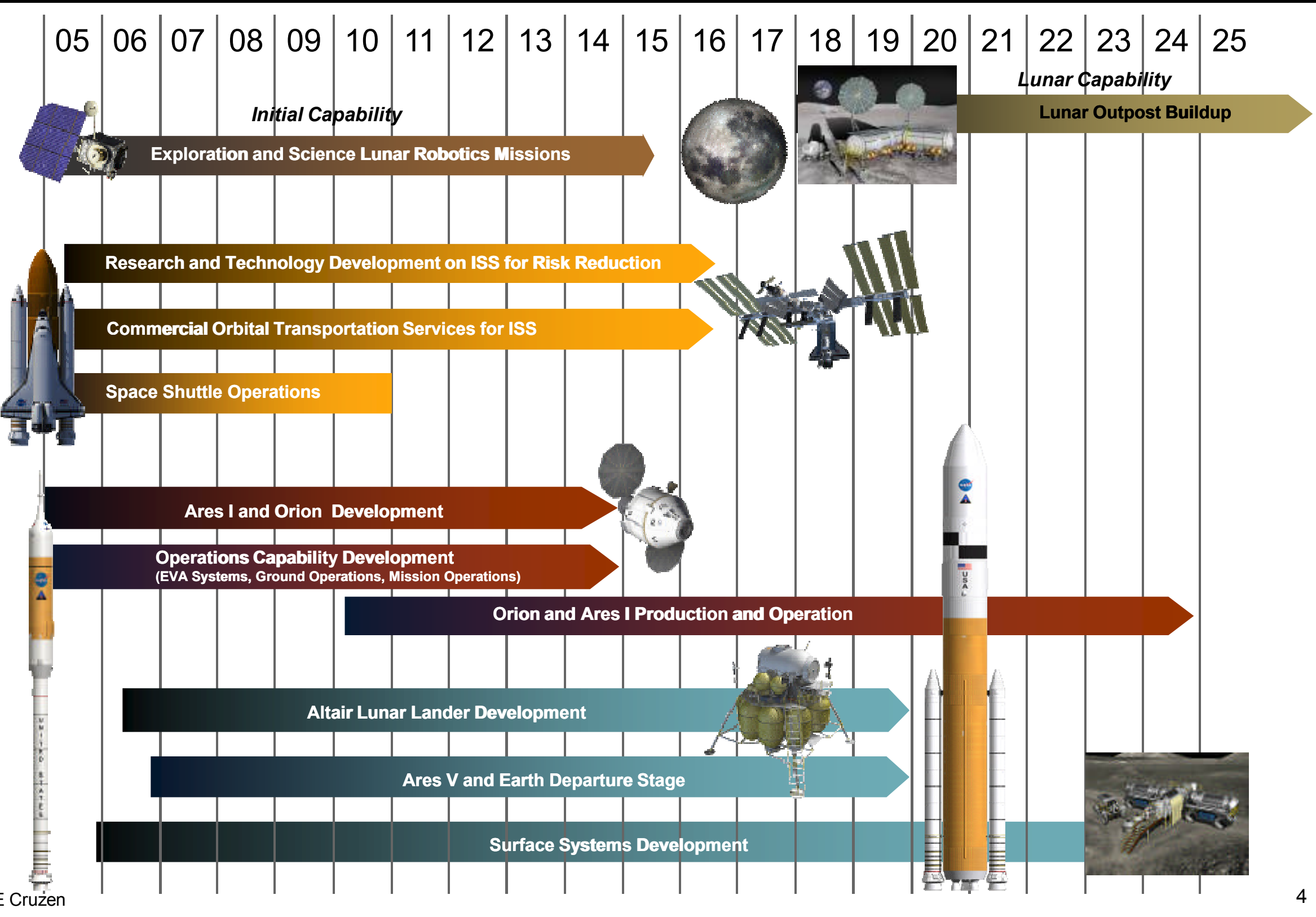




\section{Vehicles of the Constellation Program}

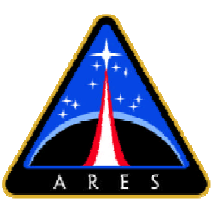

Earth

Departure Stage

$\rightarrow$

Ares V:

Heavy Lift Launch Vehicle

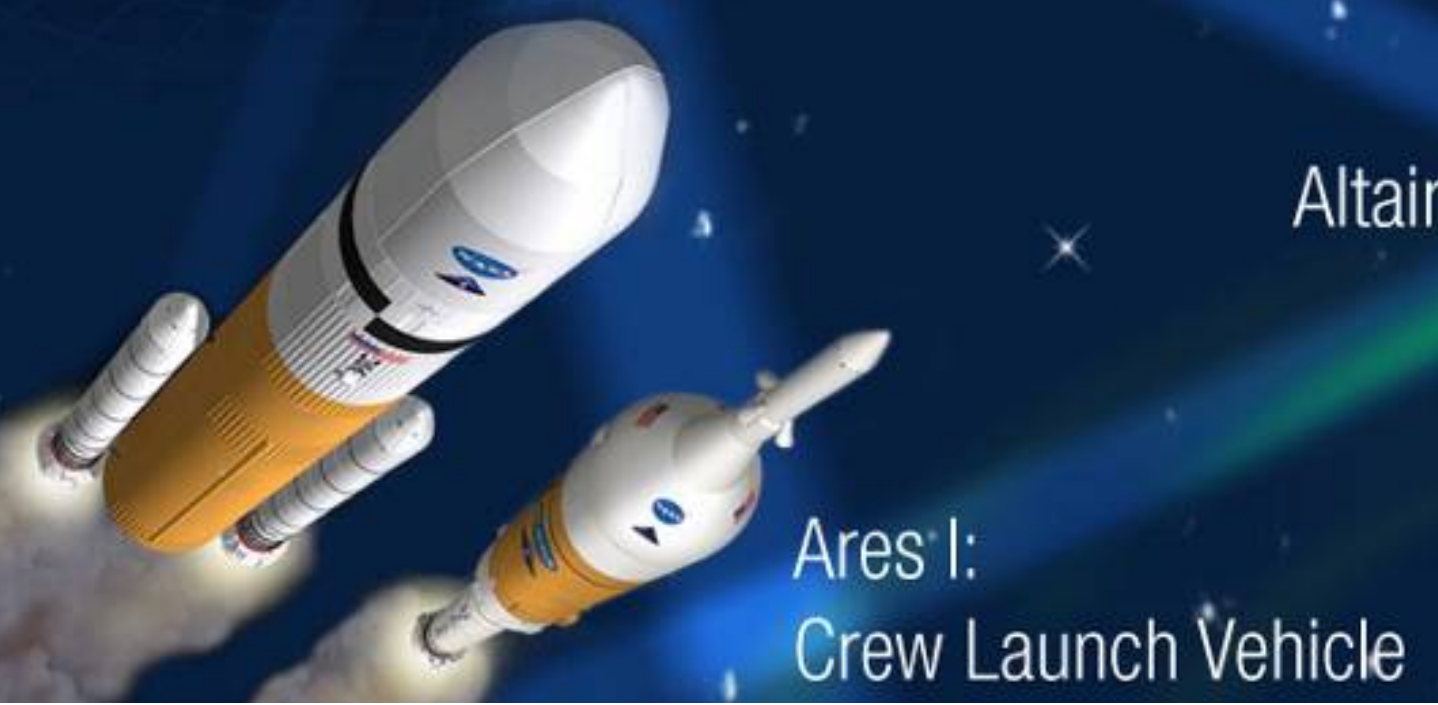

Orion: Crew Exploration Vehicle

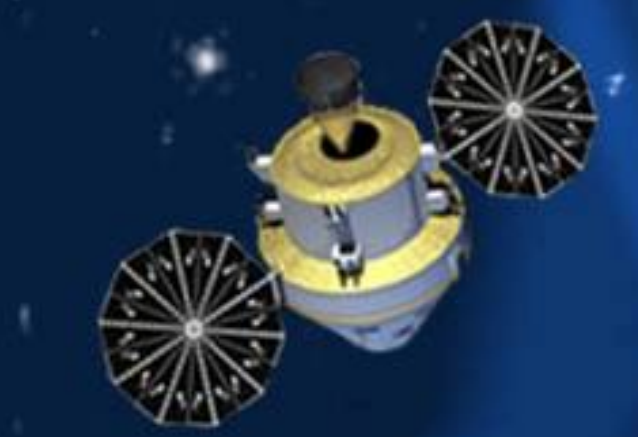




\section{Launch Vehicle Comparisons}

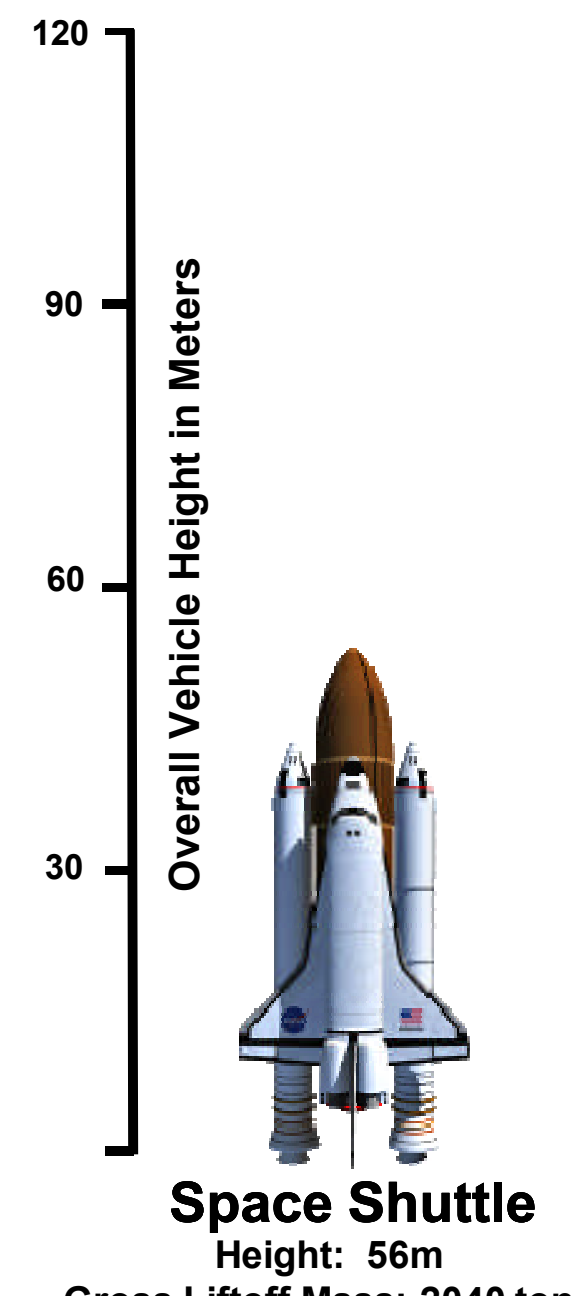

Gross Liftoff Mass: 2040 tons

25 tons to LEO

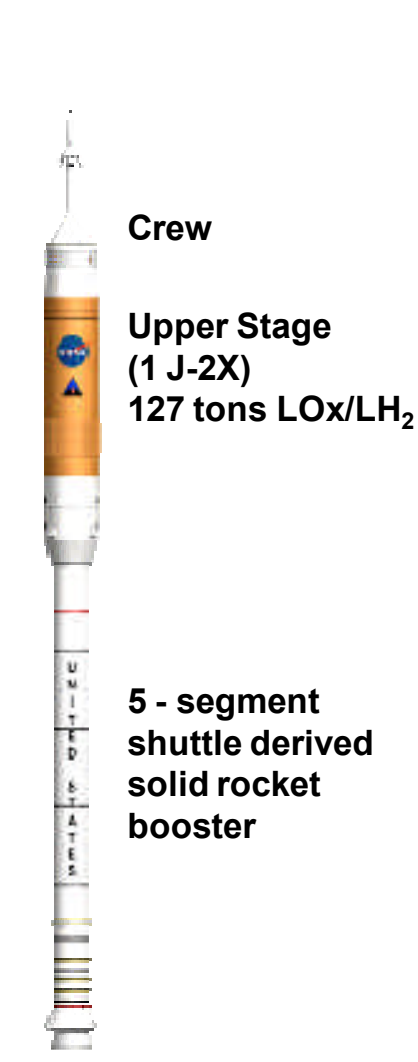

\section{Ares I}

Height: $98 \mathrm{~m}$

Gross Liftoff Mass: 910 tons

22 tons to LEO

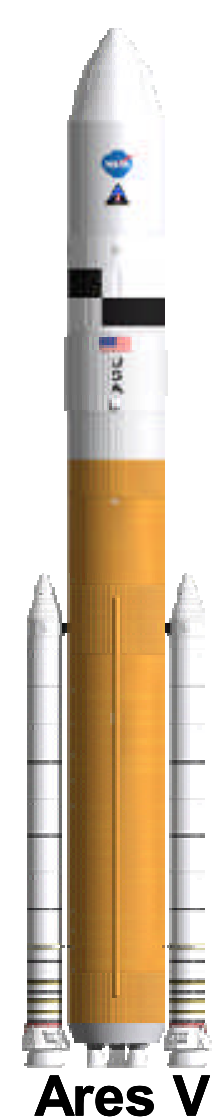

Lunar

Lander

Earth Departure

Stage (EDS) (1 J-2X)

253 tons $\mathrm{LOx} \mathrm{LH}_{2}$

Core Stage

(6 RS-68B engines)

1590 tons $\mathrm{LOx} / \mathrm{LH}_{2}$

5.5 segment 2 RSRBs

Height: $109 \mathrm{~m}$

Gross Liftoff Mass: $3310 t$

55 tons cargo to moon

66 tons to moon in dual-launch mode

150 tons to LEO
Crew

Lander

\section{S-IVB}

(1 J-2 engine)

$110 \mathrm{t}$ Lox/LH $_{2}$

S-II

( $5 \mathrm{~J}-2$ engines)

$450 \mathrm{t} \mathrm{LOx}^{-\mathrm{LH}_{2}}$

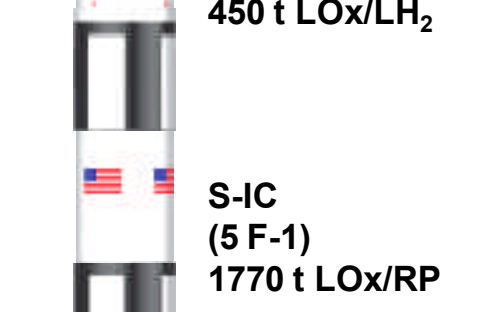




\section{Ares I Elements}

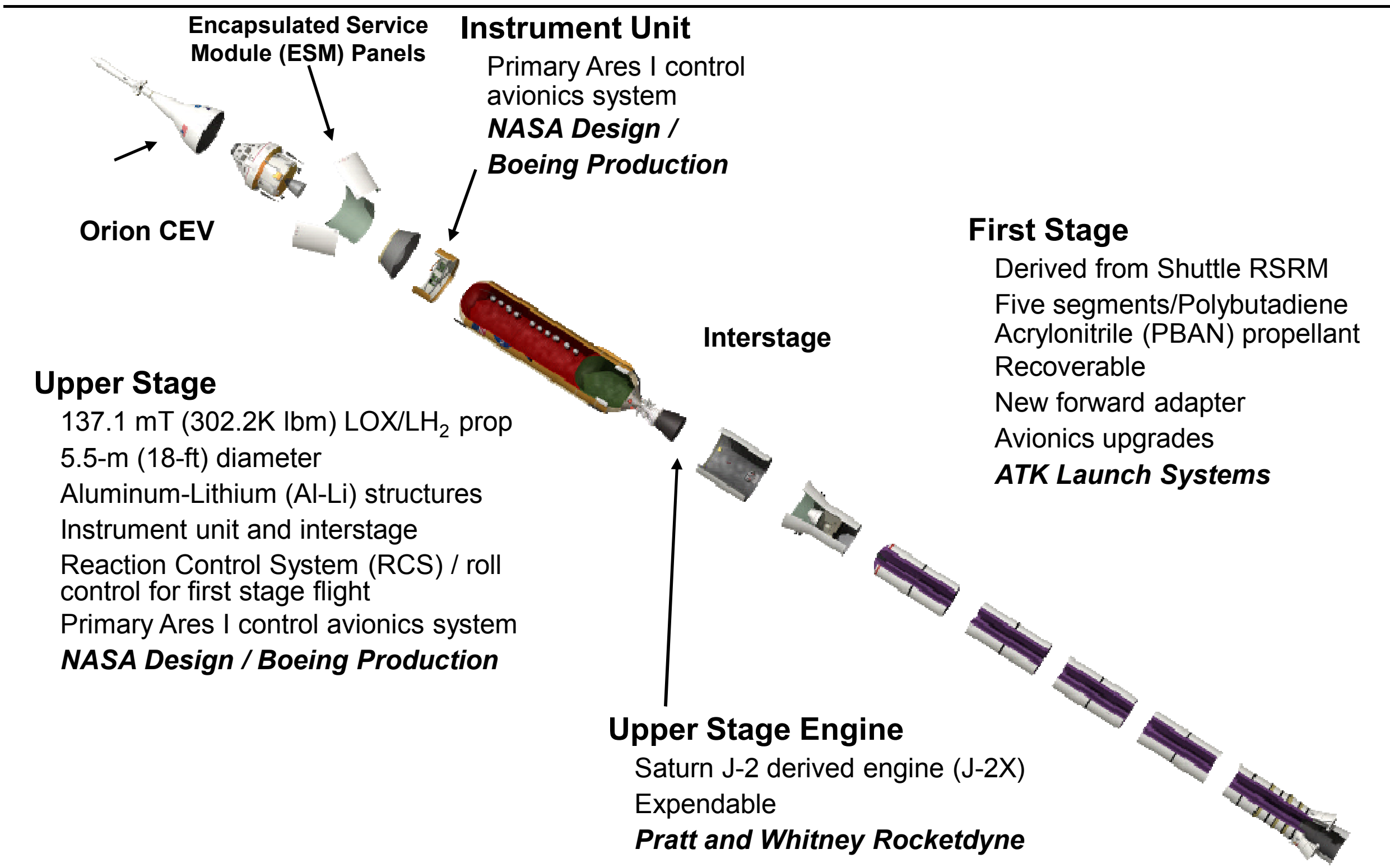




\section{Ares V Elements}

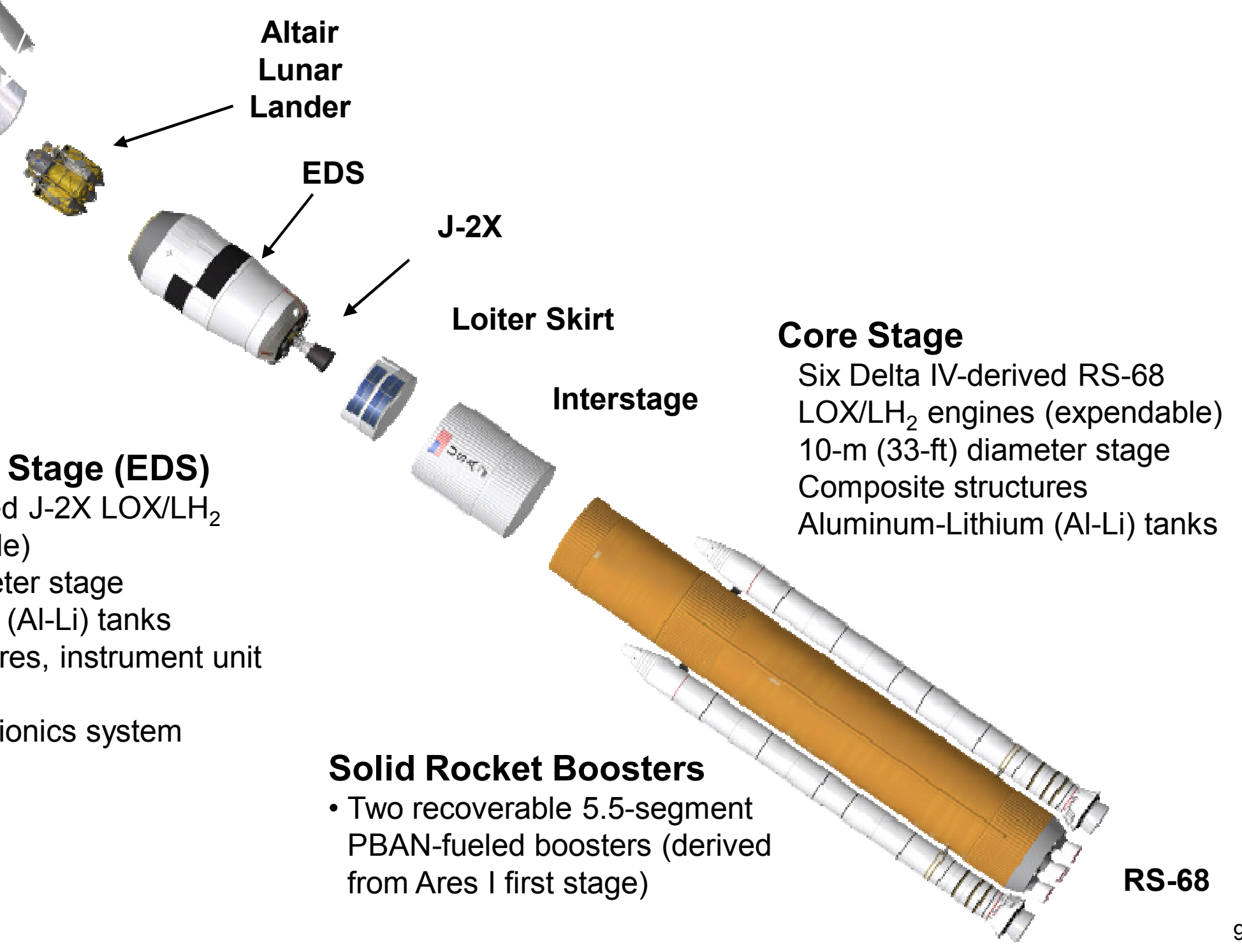


Constellation Definition of Operability:

"The ability of a system to be operated for a specified duration under specified resources."

Key Operability Components:

Duration - Time to Perform Functions

Operating Condition - Environments (Internal, External, Natural, Induced)

Capability - System and Subsystem Reliability

Resources - Everything Needed for Operation

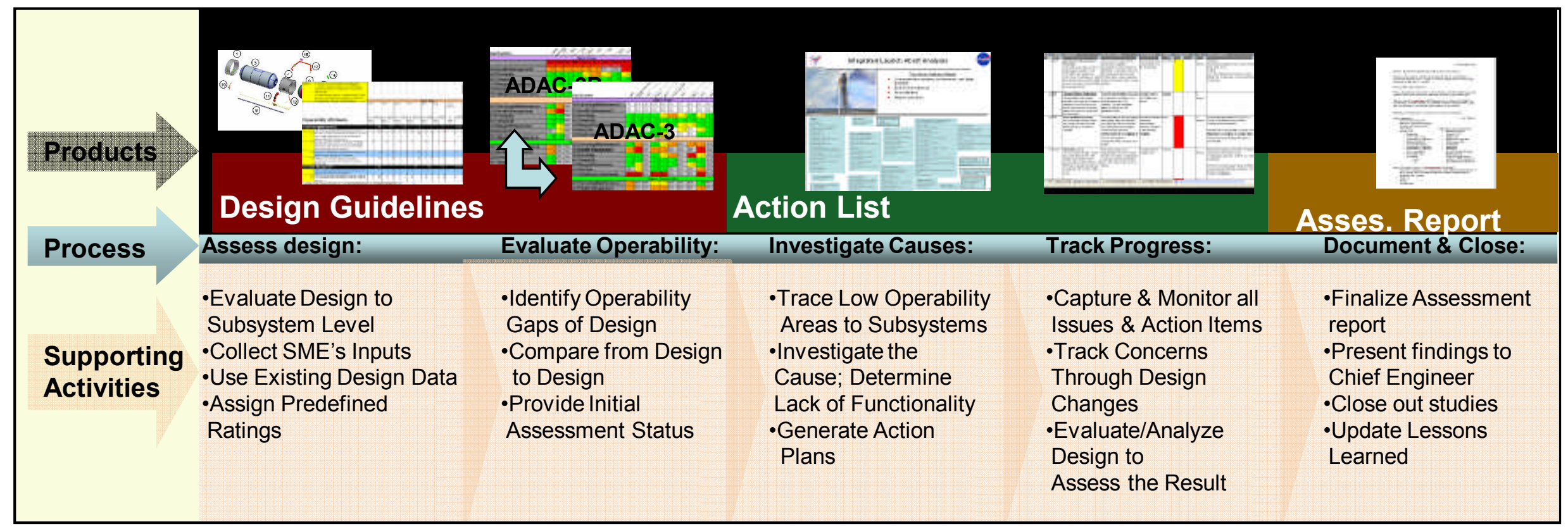




\section{Designing for Operability: Ares I Options and Examples}

\section{Manufacturing:}

- Common use elements: batteries, fluids, pyros

- Simplify systems - especially avionics

- Use of previous designs and systems

- Reduce complexity where possible

Nominal Ground Processing:

- Off-Line operations prior to vehicle stacking

- Quick transition between integration and launch pad

- Automated checkout processes utilized

- Clean pad - minimized pad activities

\section{Off-Nominal Ground Processing:}

- High reliability components

- Balance access and repair capabilities

- Advanced fault detection and diagnosis techniques in development

Flight Operations:

- Automated operation with fault management systems

- Thrust oscillation mitigation

- Contingency manual steering during ascent

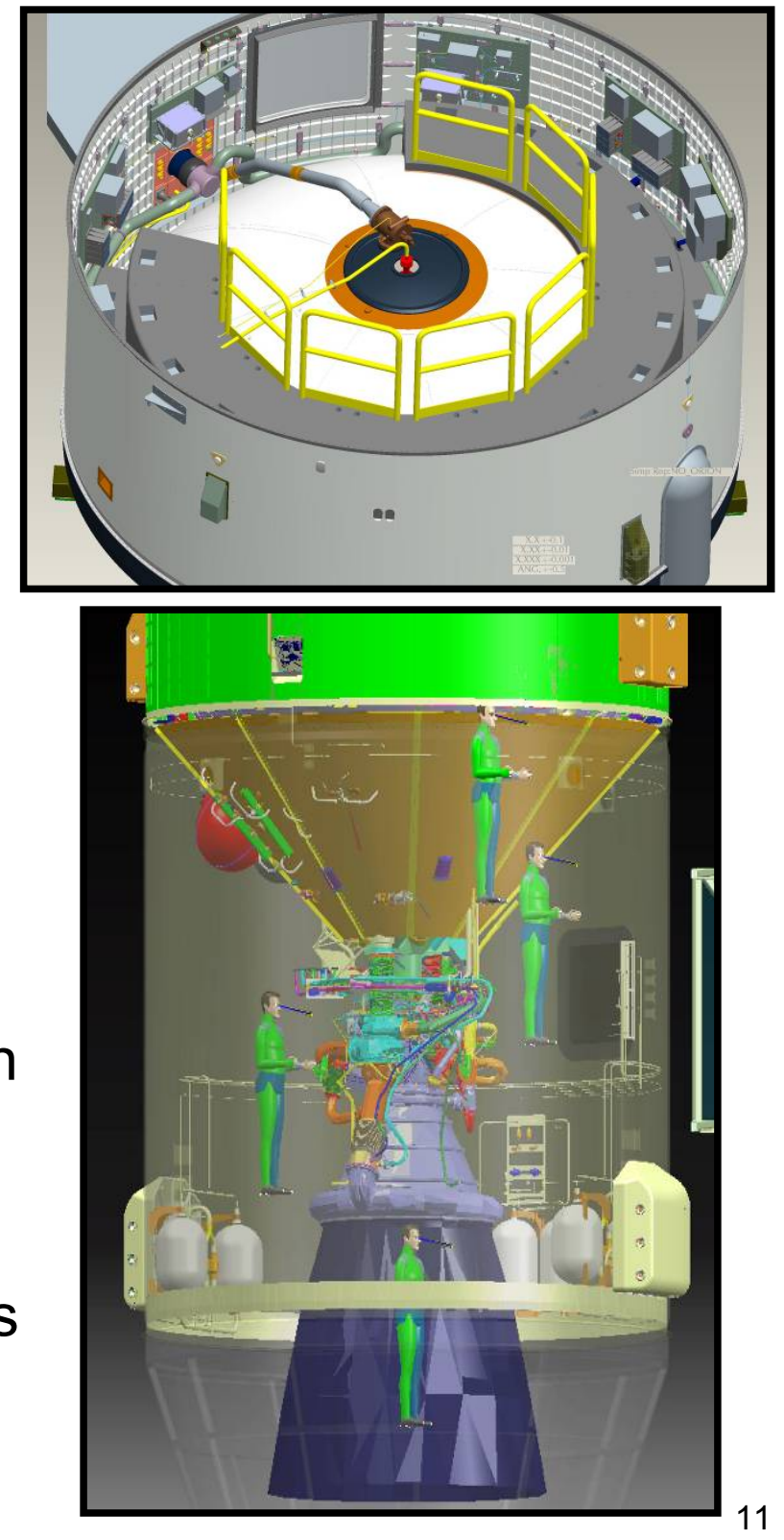




\begin{tabular}{|l|l|l|l|}
\hline & \multicolumn{2}{|c|}{ Saturn V Space Shuttle } & \multicolumn{2}{c|}{ Ares I } \\
\hline $\begin{array}{l}\text { Manufacturing } \\
\text { and } \\
\text { Transportation }\end{array}$ & $\begin{array}{l}\text { Stages Built } \\
\text { Separately } \\
\text { Manufact: approx 1 } \\
\text { year }\end{array}$ & $\begin{array}{l}\text { ET's built in } \\
\text { Louisiana, SRBs } \\
\text { processed in Utah, } \\
\text { Orbiters in FL } \\
\text { ET Manufact: } \\
\text { approx 6 months }\end{array}$ & $\begin{array}{l}\text { First Stage (FS) } \\
\text { processed in } \\
\text { Utah, Upper Stage } \\
\text { built in Louisiana } \\
\text { US Manufact: up } \\
\text { to 2 years }\end{array}$ \\
\hline $\begin{array}{l}\text { Transportation } \\
\text { Method }\end{array}$ & $\begin{array}{l}\text { S-IC \& S-II transport } \\
\text { via barge } \\
\text { S-IVB \& IU via air }\end{array}$ & $\begin{array}{l}\text { ET transport via } \\
\text { barge, SRBs via } \\
\text { rail }\end{array}$ & $\begin{array}{l}\text { FS segments } \\
\text { transport via rail } \\
\text { US via barge }\end{array}$ \\
\hline Transportation Time & Up to 70 days & Up to 2 weeks & Up to 2 weeks \\
\hline $\begin{array}{l}\text { Vehicle } \\
\text { Integration }\end{array}$ & $\begin{array}{l}\text { All Stages arrived at } \\
\text { KSC, ready to stack }\end{array}$ & $\begin{array}{l}\text { ET, SRB segments } \\
\text { arrive at KSC, } \\
\text { ready to stack } \\
\text { Orbiter processed } \\
\text { at KSC }\end{array}$ & $\begin{array}{l}\text { FS segments \& US } \\
\text { arrive at KSC, } \\
\text { ready to stack } \\
\text { Orion processed } \\
\text { at KSC }\end{array}$ \\
\hline Stacking Time & Approx 6 months & Approx 2 months & Approx 1 month \\
\hline Roll out to Pad & L-2.5 months & L-1 Month & L-7 days \\
\hline
\end{tabular}




\begin{tabular}{|l|l|l|l|}
\hline & \multicolumn{2}{|c}{ Saturn V Space Shuttle } & \multicolumn{2}{c|}{ Ares I } \\
\hline $\begin{array}{l}\text { Pad Ops and } \\
\text { Countdown }\end{array}$ & $\begin{array}{l}\text { Countdown Start: } \\
\text { L - 4 days }\end{array}$ & $\begin{array}{l}\text { Countdown Start: } \\
\text { L - 4 days }\end{array}$ & $\begin{array}{l}\text { Countdown Start: } \\
\text { L - 2 days }\end{array}$ \\
\hline Cryos Loaded & T - 9 hours & T - 8 hours & T - 6 hours \\
\hline Crew Loaded & T - 3 hours & T - 3 hours & T - 3 hours \\
\hline Internal Power & T - 50 seconds & T - 60 seconds & T - 60 seconds \\
\hline & $\begin{array}{l}3 \text { liquid stages } \\
\text { Delivered spacecraft to } \\
\text { LEO and trans-lunar } \\
\text { orbits } \\
\text { All stages disposable }\end{array}$ & $\begin{array}{l}\text { Lelivers orbiter to } \\
\text { SSMBs and 3 cryo } \\
\text { SRBs recovered, ET } \\
\text { disposable }\end{array}$ & $\begin{array}{l}\text { 1st Stage: SRB } \\
\text { (recovered) } \\
\text { Upper Stage: Cryo } \\
\text { (disposable) } \\
\text { Delivers Orion to } \\
\text { non-sustainable } \\
\text { LEO }\end{array}$ \\
\hline $\begin{array}{l}\text { MECO Time } \\
\text { \& Final Orbit }\end{array}$ & $\begin{array}{l}\text { MECO: 9min 20 sec } \\
\text { LEO: } 100 \text { nmi circ }\end{array}$ & $\begin{array}{l}\text { MECO: 8min 40sec } \\
\text { ISS LEO: 220 nmi } \\
\text { circ }\end{array}$ & $\begin{array}{l}\text { MECO: 9min 50sec } \\
\text { Orion Sep Orbit: 70 } \\
\text { nmi (-11x100 nmi) }\end{array}$ \\
\hline
\end{tabular}


The objective of this paper was to compare what Ares is doing in the area of operability requirements to what was planned on Saturn and Shuttle - and what ultimately came to fruition.

- Saturn V development was driven by performance and schedule - NOT recurring ops costs and operability.

- Shuttle development WAS driven to reduce ops cost, but may have focused too much on reusability; early unrealistic flight rate planning also decreased cost projections.

- Ares is attempting to balance design emphasis between performance, cost and long term operability.

- Ares has established processes to rank operability goals, assess their effect on the design and allocate the requirements for those deemed co'st effective by Project Management and Engineering. 


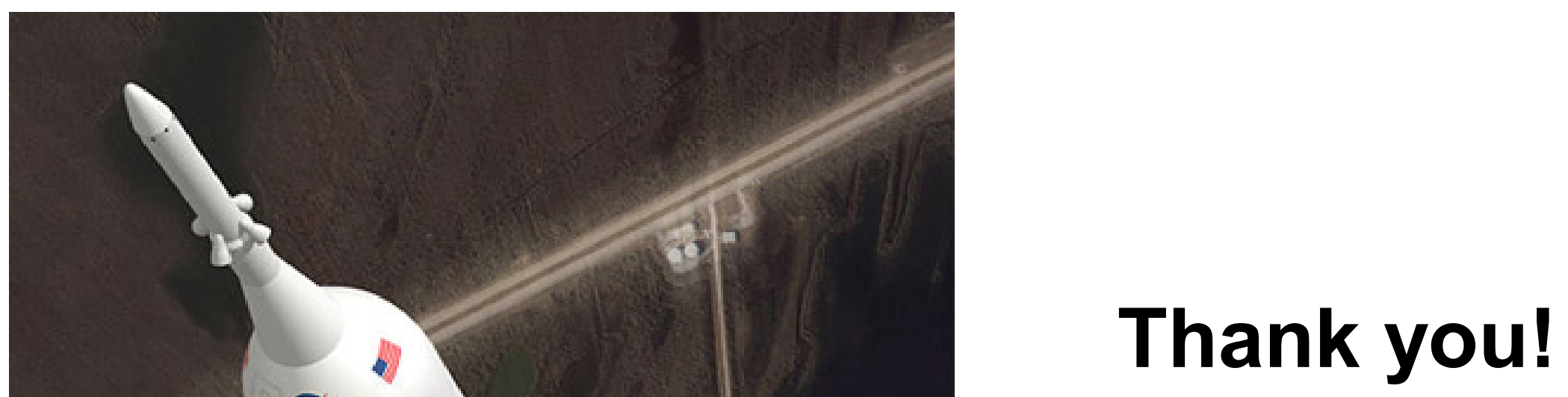

Questions? 